Mens

Revue d'histoire intellectuelle et culturelle

mens

\title{
Albert Tessier, agent de transmission d'une idée du Québec en France entre 1930 et 1950
}

\section{Brigitte Nadeau}

Volume 12, numéro 2, printemps 2012

Enjeux et modalités des transferts culturels dans la vie artistique canadienne-française de la première moitié $d u \mathrm{XX}^{\mathrm{e}}$ siècle

URI : https://id.erudit.org/iderudit/1013874ar

DOI : https://doi.org/10.7202/1013874ar

Aller au sommaire du numéro

Éditeur(s)

Centre de recherche en civilisation canadienne-française

ISSN

1492-8647 (imprimé)

1927-9299 (numérique)

Découvrir la revue

Citer cet article

Nadeau, B. (2012). Albert Tessier, agent de transmission d'une idée du Québec en France entre 1930 et 1950. Mens, 12(2), 61-101.

https://doi.org/10.7202/1013874ar

\section{Résumé de l'article}

Dans les années 1920, Albert Tessier agit comme médiateur culturel entre le régionalisme mistralien et le Québec, dans le but d'adapter l'identité canadienne-française rurale et catholique au monde moderne. Entre 1930 et 1950, il participe à la transmission, en France, d'une idée du Québec comme pays de haute moralité et de nature. Il sélectionne ses intermédiaires à partir de critères régionalistes. Il répond à la demande française, mais s’interpose comme un filtre entre le Québec et les passeurs Georges Cerbelaud Salagnac, Raoul Blanchard, Maurice Genevoix et Marie Le Franc. Tessier fait du Québec un relais en retournant à la France un régionalisme mistralien remanié. Il sert sa propre cause de consolidation de l'identité canadienne-fraçaise en proposant le Québec comme société-mémoire de la France. 


\title{
Albert Tessier, agent de transmission d'une idée du Québec en France entre 1930 et 1950
}

\author{
Brigitte Nadeau \\ Département d'histoire \\ Université Laval
}

\section{Résumé}

Dans les années 1920, Albert Tessier agit comme médiateur culturel entre le régionalisme mistralien et le Québec, dans le but d'adapter l'identité canadienne-française rurale et catholique au monde moderne. Entre 1930 et 1950, il participe à la transmission, en France, d'une idée du Québec comme pays de haute moralité et de nature. Il sélectionne ses intermédiaires à partir de critères régionalistes. Il répond à la demande française, mais s'interpose comme un filtre entre le Québec et les passeurs Georges Cerbelaud Salagnac, Raoul Blanchard, Maurice Genevoix et Marie Le Franc. Tessier fait du Québec un relais en retournant à la France un régionalisme mistralien remanié. Il sert sa propre cause de consolidation de l'identité canadienne-fraçaise en proposant le Québec comme société-mémoire de la France.

\section{Abstract}

In the 1920s, Albert Tessier acted as cultural mediator between the "régionalisme mistralien" and Quebec, in the hopes of adapting the French Canadian rural and catholic identity to the modern world. Between 1930 and 1950, he participated in the transmission, in France, of a certain idea of Quebec as a country of high morality and nature. He selected his intermediaries through regionalist criteria. He answers French 
expectations, but places himself as a filter between Quebec and people like Georges Cerbelaud Salagnac, Raoul Blanchard, Maurice Genevoix and Marie Le Franc. Tessier transforms Quebec into a relay by sending back to France a revised "régionalisme mistralien". In this, he serves his own cause, consolidating French Canadian identity by proposing Quebec as a "société-mémoire" of France.

L'étude des transferts culturels se fait le plus souvent du point de vue des récepteurs. L'intérêt est principalement porté sur l'emprunt à la culture autre qui apparaît comme un choix fait par un médiateur. Nous pouvons cependant opter pour une définition plus large du transfert culturel et tenir compte, comme le fait Martin Doré dans un ouvrage récent sur les passeurs en histoire du livre, "non seulement du résultat final, mais aussi du processus en entier, avec son origine, son contenu et les agents ayant procédé au déplacement [...] de l'objet ${ }^{1} "$.

Pour faciliter la compréhension, le terme "passeur " désigne dans ce texte les agents en processus d'acquisition d'éléments culturels étrangers, alors que le terme " médiateur " renvoie à la diffusion de l'emprunt dans la culture d'accueil. Cette distinction, tout artificielle qu'elle soit, a le mérite de clarifier une situation complexifiée par l'implication de plus d'un intermédiaire dans un même transfert. Elle facilite aussi l'observation de certains moments isolés du processus de transmission. Nous nous attarderons sur un moment de ce processus, antérieur à la médiation comme telle, au cours duquel un agent peut influencer les choix faits par les passeurs. L'objectif est d'examiner le rôle que joue l'un de ces agents, l'abbé Albert Tessier (1895-1976), dans la transmission, à des passeurs français, d’une image du Québec

1 Martin Doré, «Fonctionnement du transfert culturel et examen d'un cas francocanadien dans le marché du livre, 1970-2000", dans Marie-Pier Luneau et al. (dir.), Passeurs d'histoire(s) : figures des relations France-Québec en histoire du livre, Québec, Les Presses de l'Université Laval, 2010, coll. «Cultures québécoises », p. 446. 
comme pays de haute moralité et de nature dans les années 1930 et 1940 .

Albert Tessier a exercé une influence notable sur la culture québécoise des deux décennies précédant la Révolution tranquille, notamment dans le domaine de l'éducation ${ }^{2}$. Son ouvre demeure toutefois peu étudiée, sans doute parce que Tessier s'est fait une réputation peu enviable de traditionaliste en faisant de la propagande régionaliste le fer de lance de son action sociale. Son traditionalisme ne se traduisait cependant pas par un combat contre le changement et la modernité; il s'exprimait plutôt par des entreprises de sauvegarde de l'identité canadienne-française, comme en témoigne son parcours de communicateur et d'éducateur.

Albert Tessier est né dans une famille d'agriculteurs à SainteAnne-de-la-Pérade. Enfant de santé fragile, plus contemplatif qu'actif, il développe tôt un sens aigu de l'observation et une passion pour la photographie. Après les études classiques au Séminaire Saint-Joseph de Trois-Rivières, il poursuit en théologie au Grand Séminaire. Il est diplômé de l'Université Laval en 1916 et ordonné prêtre en 1920. Il obtient un doctorat en théologie de l'Angelicum de Rome, où il étudie de 1921 à 1923; il passe ensuite quelque temps à l'Institut catholique de Paris, en 1923-1924, avant de revenir enseigner au Séminaire de Trois-Rivières ${ }^{3}$. Dès son retour d'Europe en 1924, il pense à préparer les fêtes du tricentenaire de la ville de Trois-Rivières, qui aura lieu en 1934. C'est pour lui l'occasion d'amorcer une campagne régionaliste qui établira sa réputation de propagandiste. Il occupait le poste de préfet des études depuis 1927 lorsque le cardinal archevêque de Québec, Mrr Rodrigue Villeneuve, le nomme inspecteur

\footnotetext{
2 Tessier est décoré de la médaille d'or du Mérite scolaire en 1947 (Georges Panneton et Antonio Magnan, "Prélats de la Maison du Pape : Tessier (Monseigneur Albert) ", Le diocèse de Trois-Rivières 1962, Trois-Rivières, Bien public, 1962, p. 29).

3 Tessier enseigne les belles-lettres au Séminaire de Trois-Rivières en 1920-1921. Après l'obtention de son doctorat, il enseigne en rhétorique jusqu'en 1929, l'histoire du Canada de 1929 à 1938 et la géographie de 1931 à 1933. En 1937, il enseigne la théologie dogmatique au Grand Séminaire (Ibid.).
} 
propagandiste de l'Enseignement ménager dans la province de Québec, en 1937. Il sera visiteur en chef des écoles ménagères à partir de 1947 jusqu’à sa retraite, en 1965. Il est entre-temps nommé prélat de la Maison du Pape en 1949. Éditeur et auteur prolifique, il est aussi un pionnier du cinéma québécois, qu'il aborde en autodidacte en $1925^{4}$. Il a tourné et présenté de nombreux films sur l'éducation, la religion, la nature et la vie rurale au Québec 5 .

Albert Tessier avait à cour de partager sa passion pour la culture du Québec et il diffusait largement ses thèses identitaires aussi bien auprès de la population locale que de ses nombreux contacts étrangers, comme nous le verrons dans le présent article, qui se divise en cinq parties. En premier lieu, l'engagement de Tessier comme médiateur entre le régionalisme provençal de Frédéric Mistral (1830-1914) et le Québec explique la place que prend la propagande régionaliste identitaire dans son œuvre. Le deuxième point relève les critères présidant au choix de ses intermédiaires. La troisième partie traite de la façon dont Tessier répond à une certaine quête française d'une moralité catholique, et la quatrième rend compte de son intervention auprès des visiteurs français en quête de la nature primitive. Cette étude des échanges entre les passeurs français et Tessier permet de voir comment ce dernier profite de ses contacts pour renforcer sa propagande identitaire au Québec. Le dernier point montre comment Tessier renvoie vers la France, par l'intermédiaire de quelques passeurs, les valeurs qu'il y avait lui-même empruntées, bouclant la boucle de son projet identitaire. Il participe ainsi à la création d'une image du Québec comme société-mémoire de la France.

${ }^{4}$ Le gouvernement du Québec crée, en 1980, le prix Albert-Tessier, la plus haute distinction accordée à un cinéaste, pour souligner son travail de pionnier du cinéma (Yves Lever, Histoire générale du cinéma au Québec, Montréal, Éditions du Boréal, 1995, p. 58).

5 Michel Coulombe et Marcel Jean (dir.), "Tessier, Albert ", Le dictionnaire du cinéma québécois, Montréal, Éditions du Boréal, 1999, p. 617-618. 


\section{La propagande régionaliste identitaire de l'abbé Albert Tessier}

Avant de participer, à l'instar de nombreux intellectuels québécois, à la propagande du Québec en France dans les années 1930 et 1940, Albert Tessier remplit, dans les années 1920, un rôle de médiateur culturel en instaurant en Mauricie un régionalisme inspiré de l'action de Frédéric Mistral en Provence. Tessier découvre l'œuvre littéraire régionaliste de Mistral dans les années 1910 par l'intermédiaire de l'abbé Joseph-Gérin Gélinas (1874-1927), professeur de rhétorique au Séminaire Saint-Joseph de Trois-Rivières. En lisant Mistral, Gélinas « en profitait pour nous prêcher l'attachement au milieu et aux gens qui nous entourent ${ }^{6}$ ", se souvient Tessier. Mistral devient dès lors pour lui un sujet d'admiration. Il retient de la lecture assidue de son ouvre un passage qu'il cite encore de mémoire en 1975 :

À cette heure, j'avais mes 21 ans. Le pied sur le seuil du mas paternel, les yeux tournés vers les Alpilles, en moi-même et de moi-même, j’ai pris la résolution de relever, de raviver en Provence le sentiment de race que je voyais s'annihiler sous l'éducation fausse et antinaturelle des écoles; de provoquer cette résurrection par la restauration de la langue naturelle et historique du pays, à laquelle les écoles font toutes une guerre à mort, de rendre la voix au provençal parlé par la flamme de la divine poésie?.

Tessier note dans ses Souvenirs en vrac que Mistral lui « [...] inspirera dans la suite une bonne part de [ses] initiatives régionalistes et patriotiques ${ }^{8}$ ».

Lors de son voyage d'études en Europe de 1921 à 1924', une visite au pays de Mistral le conforte dans son projet d'appliquer en

\footnotetext{
${ }^{6}$ Albert Tessier, Souvenirs en vrac, Sillery (Québec), Éditions du Boréal Express, 1975, p. 62.

7 Frédéric Mistral, Mémoires et récits, 1904, cité dans Tessier, Souvenirs en vrac, p. 62.

${ }^{8}$ Tessier, Souvenirs en vrac, p. 62.

9 Tessier est à Rome de septembre 1921 à juin 1923 et à Paris d'octobre 1923 à l'été 1924 (Ibid., p. 88, 111, 112, 123).
} 
Mauricie les principes du régionalisme provençal. Il entreprend donc, dès son retour, un projet d'éveil de la population à la fierté et à l'amour du petit pays. Sa grande préoccupation, celle qui sera le fil conducteur de toute sa carrière, y compris dans ses échanges avec les passeurs français qui lui rendent visite en Mauricie dans les années 1930 et 1940, est de consolider l'identité canadienne-française rurale et catholique qu'il entend intégrer au mode de vie moderne. Il travaille ainsi assidûment au développement social, économique, industriel et agricole de sa région dans les années 1920 et 1930. Il adopte des stratégies modernes pour rejoindre son public, présentant, par exemple, des films dans les campagnes et les villages reculés. Il tente de moderniser son enseignement en remplaçant les références françaises par des éléments de la culture québécoise familière à ses élèves. Il remplace des cours magistraux par des activités pédagogiques participatives, malgré les objections que ces méthodes nouvelles suscitent au sein du très conservateur milieu clérical trifluvien ${ }^{10}$. Son dynamisme, son implication dans la vie culturelle et son souci constant d'éduquer les foules lui ont valu d'être qualifié " d'éveilleur intellectuel ${ }^{11}$ " dans son milieu.

Entre 1924 et 1937, Tessier enseigne au Séminaire Saint-Joseph de Trois-Rivières et son action régionaliste se concentre en Mauricie. Lorsqu'il remplit les fonctions d'inspecteur propagandiste de l'enseignement ménager et de visiteur en chef des écoles ménagères de la province de Québec, de 1937 à 1965, il élargit sa définition du régionalisme pour l'adapter à toutes les régions et en assurer la survie : "Le régionalisme constitue la mise en valeur intelligente, ordonnée, méthodique des virtualités matérielles et spirituelles que le bon Dieu a mises à notre disposition dans un milieu à une époque donnée ${ }^{12}$ ",

${ }^{10}$ Voir Brigitte Nadeau, Albert Tessier intermédiaire culturel régionaliste : l'image au service d'une propagande, mémoire de maîtrise, Département d'histoire, Québec, Université Laval, 2004.

11 Clément Marchand, "Préface ", dans Albert Tessier, Mon enfance au Bas-deSainte-Anne (1895-1910), Trois-Rivières, Éditions du Bien public, 1975, p. 3.

12 Albert Tessier dans Le Nouvelliste, 26 novembre 1938, cité dans René Verrette, "Le régionalisme mauricien des années trente ", Revue d'histoire de l'Amérique française, vol. 47, n 1 (été 1993), p. 28. 
écrit-il. Il diffuse alors largement, par l'intermédiaire de la photographie, du cinéma et de la publication d'ouvrages propagandistes, des images qui participent à la construction d'une identité canadienne-française fondée sur des valeurs traditionnelles. La photographie Mains puissantes (voir la figure 1), publiée en 1942, évoque ainsi la valeur de la prière et témoigne de son implication dans la valorisation de la religion catholique, alors que la photographie Comme ceux d'autrefois (voir la figure 2), parue en 1945, associe la vigueur et la salubrité de la vie dans la nature à l'exemple des colons d'autrefois. Ces ouvres illustrent deux de ses très populaires "albums Tavi ${ }^{13}$ ".

Après avoir étendu son régionalisme de la Mauricie à l'ensemble du Québec, Tessier élargit encore son action en s'adressant, à l'aide des mêmes thématiques, à des intermédiaires qui transmettront sa conception du Québec en France. Tessier touche ces passeurs français en leur présentant une image familière de la société canadiennefrançaise façonnée, en majeure partie, à partir du régionalisme de Mistral.

Le régionalisme français dont se réclame Tessier prend la forme d'un discours idéologique fortement teinté de nationalisme. La France répand, à l'époque où Tessier fait ses études en Europe, l'image du pays assimilé à une merveilleuse mosaïque où les singularités locales sont des joyaux qui enrichissent le trésor national ${ }^{14}$. Anne-Marie Thiesse explique le fondement du concept : « L'amour pour la petite patrie est déclaré naturel, comme celui de l'enfant pour sa mère, à la différence de l'amour pour la grande Patrie qui ne saurait résulter que d'une éducation civique ${ }^{15}$. " L'école enseigne donc l'amour et la

${ }_{13}$ Albert Tessier, Femmes de maison dépareillées, Montréal, Fides, 1942, coll. «Les beaux albums Tavi », $\mathrm{n}^{\circ}$ 1; Albert Tessier, C'est l'aviron qui nous mène!, Montréal, Fides, 1945, coll. « Les beaux albums Tavi », $\mathrm{n}^{\circ} 4$.

${ }_{14}$ Anne-Marie Thiesse, Ils apprenaient la France : l'exaltation des régions dans le discours patriotique, Paris, Éditions de la Maison des sciences de l'homme, 1997, p. 3-7.

15 Ibid., p. 8. 


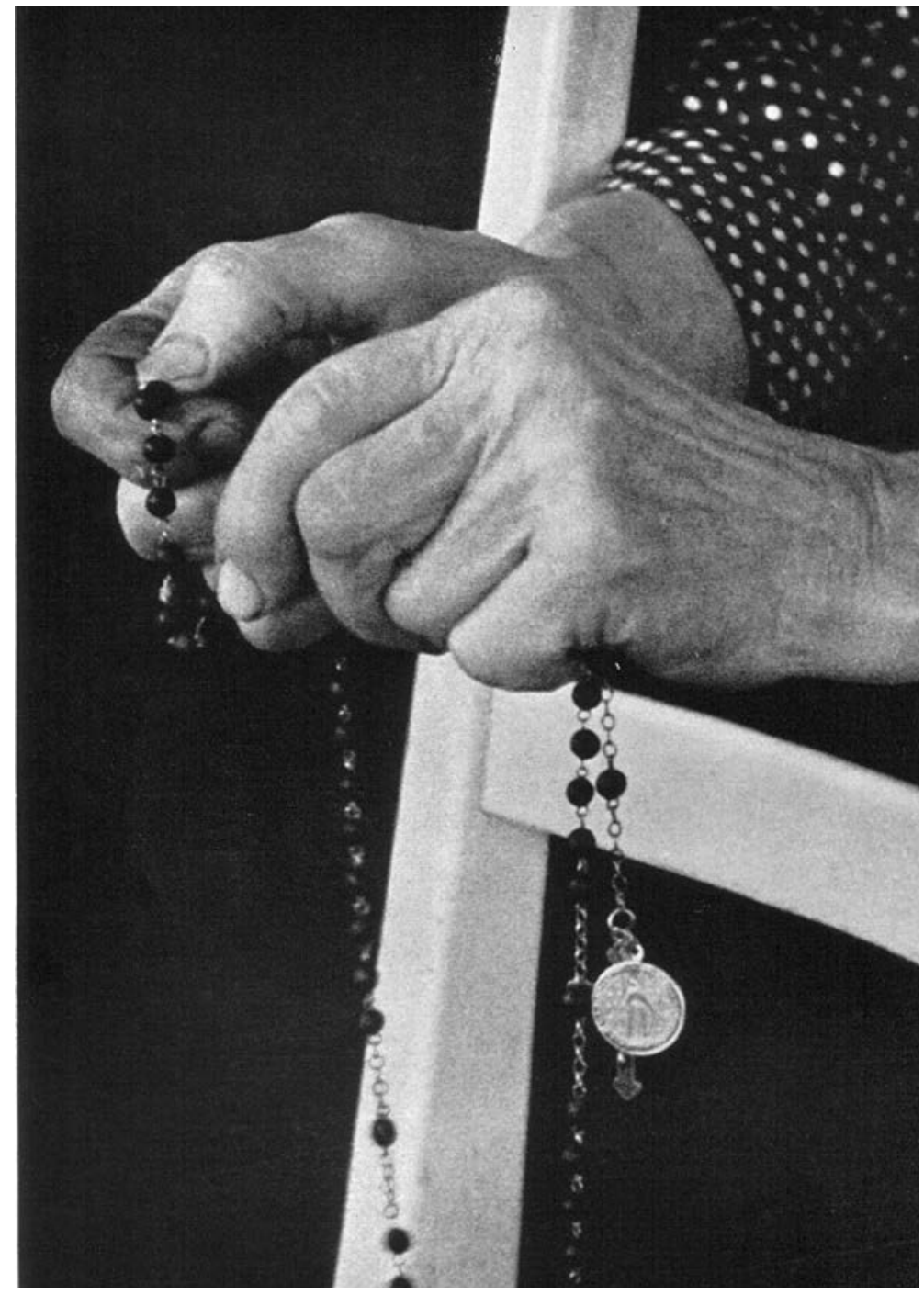

Figure 1. Albert Tessier, Mains puissantes, photographie noir et blanc, 20,4 x $14 \mathrm{~cm}$, 1942, dans Albert Tessier, Femmes de maison dépareillées, Montréal, Fides, 1942, coll. "Les beaux albums Tavi », $\mathrm{n}^{\circ} 1$, p. 10. 


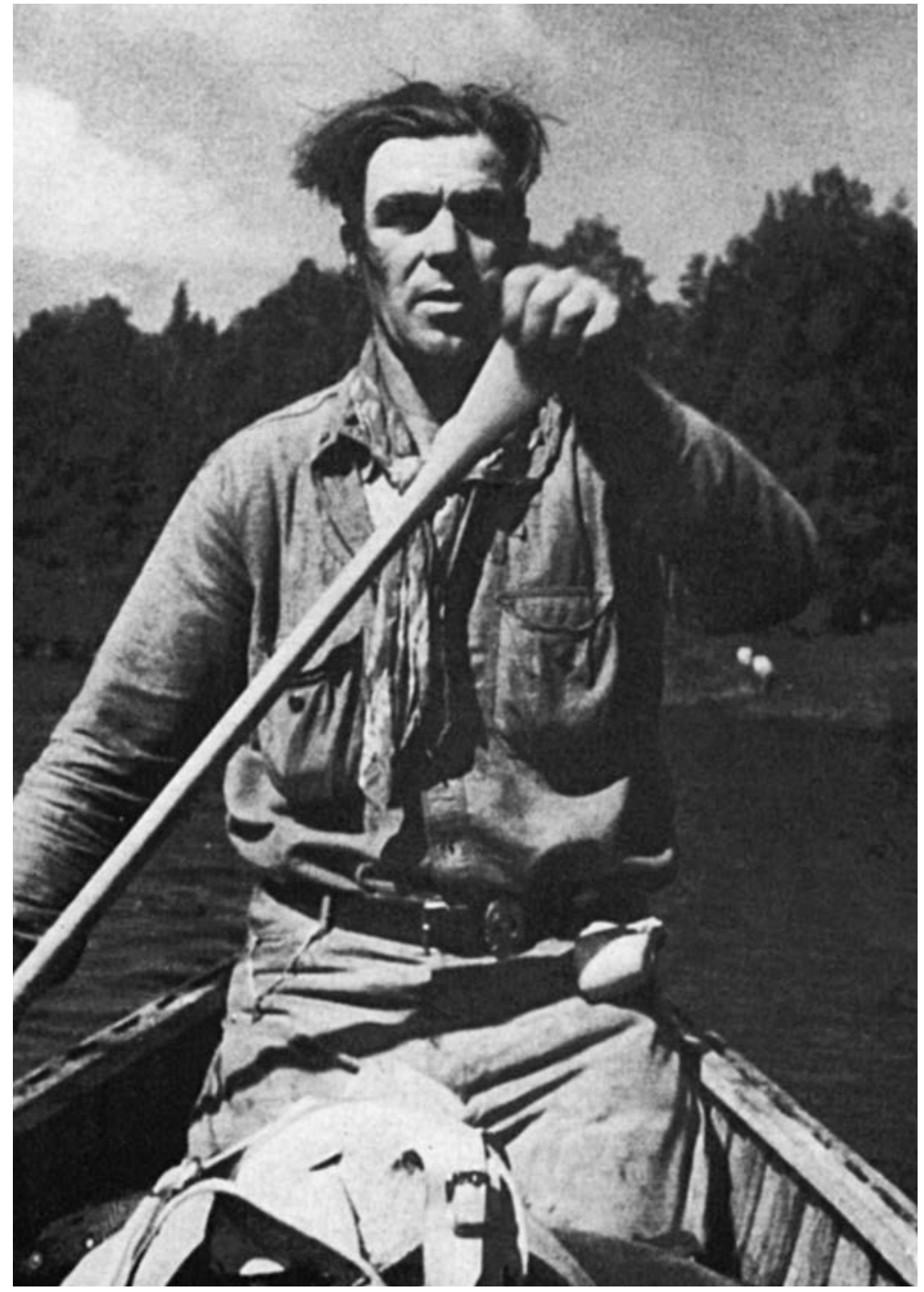

Figure 2. Albert Tessier, Comme ceux d'autrefois, photographie noir et blanc, 20,2 x 14 cm, 1945, dans Albert Tessier, C'est l'aviron qui nous mène!, Montréal, Fides, 1945, coll. "Les beaux albums Tavi », n 4, p. 6. 
fierté de la petite patrie aux enfants pour insérer ensuite leur petit monde dans le grand ${ }^{16}$.

La Troisième République (1870-1940), même si elle reconnaît certaines différences entre les régions, cherche à implanter une langue française commune, ce qui provoque une levée de boucliers des milieux littéraires régionaux dont le but premier est de lutter contre l'hégémonie culturelle parisienne. L'abbé Tessier s'inspire donc d'un régionalisme littéraire soucieux de la survivance de cultures et d'identités régionales, tel que le concevait Mistral au XIX ${ }^{\mathrm{e}}$ siècle.

L'élaboration du projet régionaliste de l'abbé Tessier et le cour de son action se situent dans la période de l'entre-deux-guerres. Le nationalisme et le régionalisme culturel sont à cette époque d'importants sujets de discussion dans les journaux québécois, surtout montréalais ${ }^{17}$. Le conservatisme du milieu intellectuel mauricien met le régionalisme de l'abbé Tessier à l'abri de ces polémiques. Cependant, sa deuxième phase d'activité régionaliste, en débordant hors des frontières de la Mauricie, le propulse dans les remous provoqués par les changements sociaux précurseurs de la Révolution tranquille. Son régionalisme est d'autant plus mal reçu à l'échelle provinciale qu'il est jumelé à la modernisation de l'enseignement dans les écoles ménagères que nombre d'intellectuels jugent dépassées et souhaiteraient voir simplement disparaître.

Le mouvement régionaliste de Tessier trouve des appuis parmi les penseurs qui cherchent à adapter la culture nationale à la modernité. Le journaliste André Laurendeau, qui sera l'un des instigateurs du néonationalisme ${ }^{18}$ dans les années 1940 et 1950 , le défend : «On

16 Ibid., p. 17-18. Cette forme d'éducation patriotique est commune à plusieurs pays d'Europe qui ont un système d'enseignement de masse. Thiesse cite les cas de la Scandinavie, de l'Allemagne et de la Suisse.

17 Esther Trépanier, Peinture et modernité au Québec 1919-1939, Québec, Nota bene, 1998, p. 31.

${ }^{18}$ Le néonationalisme " [...] se caractérise par une volonté de repenser le vieux nationalisme afin de l'adapter aux réalités et aux exigences de la société urbaine et industrielle qu'est devenu le Québec. Une telle mise à jour implique deux 
craint ce mot "régionalisme" parce qu'on croit qu'il signifie un rétrécissement. C'est mal l'entendre. J'invite les dissidents à rendre visite à l'abbé Tessier, aux Trois-Rivières; on y est régionaliste fort intelligemment ${ }^{19}$."

Tessier occupe, parmi les penseurs québécois des décennies 1930 et 1940, une position ambiguë, pris entre un clergé traditionaliste qui le considère trop progressiste et des intellectuels tournés vers la modernité qui le jugent conservateur. Condamné par les uns et les autres, il est laissé pour compte après la Révolution tranquille : il ne peut ni célébrer la modernité, puisqu’il semble avoir perdu son pari d'intégrer les valeurs ancestrales dans la nouvelle société, ni pleurer sur les traditions perdues, puisqu'il a tenté d'inclure le progrès comme une valeur positive de l'ère nouvelle. Le médiateur culturel est ainsi "sans passé et sans avenir [...], entre deux, transfuge ${ }^{20}$ ». Sans doute le propagandiste déçu trouve-t-il, auprès d'interlocuteurs issus du mouvement catholique français qui partagent plusieurs de ses valeurs ${ }^{21}$, une justification à sa démarche.

choses : que l'on préserve ce qui fait le cœur de la doctrine nationaliste, c'est-àdire l'affirmation de l'identité nationale du peuple canadien-français et de son vouloir-vivre collectif, tout en renonçant par ailleurs aux contenus traditionalistes et réactionnaires associés jusque-là à cette doctrine, pour les remplacer par d'autres qui soient mieux accordés aux données sociologiques et politiques actuelles et donc plus propices à l'action constructive " (Paul-André Linteau et al., Histoire du Québec contemporain, t. 2 : Le Québec depuis 1930, Montréal, Éditions du Boréal, 1995 [1989], p. 356.

19 André Laurendeau, cité dans Tessier, Souvenirs en vrac, p. 136. Tessier ne donne pas la date de l'article signé par le " jeune et ardent André Laurendeau ».

20 Henriette Asséo, "Autour de la notion d'intermédiaire culturel ", dans Michel Vovelle (dir.), Les intermédiaires culturels, actes du colloque du Centre méridional d'histoire sociale, des mentalités et des cultures de 1978, Aix-en-Provence, Publications Université de Provence; Paris, Honoré Champion, 1981, p. 628.

21 Les échanges intellectuels entre la France et le Québec qui ont lieu de 1930 à 1960 sont majoritairement le fait de groupes catholiques qui peuvent défendre autant des idées progressistes que conservatrices. Voir Stéphanie Angers et Gérard Fabre, Échanges intellectuels entre la France et le Québec (1930-2000) : les réseaux de la revue Esprit avec La Relève, Cité libre, Parti pris et Possibles, Québec, Les Presses de l'Université Laval, 2004, coll. "Sociologie contemporaine ». 


\section{Exporter le Québec comme pays de haute moralité et de nature}

Tessier n'explique jamais son allégeance politique, il évite de mêler la politique à sa campagne régionaliste, s'assurant l'adhésion du plus grand nombre et réduisant au minimum les frictions qui risquent toujours de l'opposer à ses supérieurs. Pendant ses études, il s'intéresse au régionalisme français et aux penseurs de différents horizons influencés par Mistral comme Charles Maurras (1868-1952), qui défend le royalisme contre la République ${ }^{22}$, Jean Charles-Brun (1870-1946) ${ }^{23}$, théoricien de la « Fédération régionaliste français $\mathrm{e}^{24}$ " ou Maurice Barrès (1862-1923), régionaliste et nationaliste républicain $^{25}$. Tessier est toutefois davantage attiré par les aspects culturels et littéraires du régionalisme que par les engagements politiques qui en découlent.

Lors de son voyage d'études en Europe, Tessier entre en contact avec des personnalités françaises qui s'intéressent au Québec, sans se soucier outre mesure de leur orientation politique. L'attachement sentimental particulier voué à un petit pays d'origine, très important pour l'idéologie régionaliste, apparaît comme le critère premier à partir duquel il établit ses relations. Son ex libris (voir la figure 3) gravé par Rodolphe Duguay, inspiré par son pseudonyme "Le Tisserand ", évoque l'établissement de ces liens qui seront pour la plupart de longue durée.

22 Yves-Marie Hilaire, "Chapitre VIII : 1900-1945 : l'ancrage des idéologies », dans Jean-François Sirinelli (dir.), Histoire des droites en France, t. 1 : Politique, Paris, Gallimard, 2006 [1992], coll. " Tel Gallimard ", p. 532; Charles Camproux, "Frédéric Mistral, 1830-1914 », Encyclopedia Universalis, Paris, Encyclopædia Universalis, 1989, corpus 15, p. 473.

${ }^{23}$ Charles-Brun crée à Paris, en 1898, la Ligue occitane, inspirée du mistralisme (Claude Mauron, Frédéric Mistral, Paris, Librairie Arthème Fayard, 1993, p. 317).

${ }^{24}$ Voir Julian Wright, The Regionalist Movement in France, 1890-1914: Jean CharlesBrun and French Political Thought, Oxford, Clarendon, 2003.

${ }^{25}$ Hilaire, "Chapitre VIII : 1900-1945 : l'ancrage des idéologies », p. 523; voir Yves Chiron, Barrès et la terre, Paris, Sang de la terre, 1987; Yves Chiron, Maurice Barrès : le prince de la jeunesse, Paris, Perrin, 1986. 


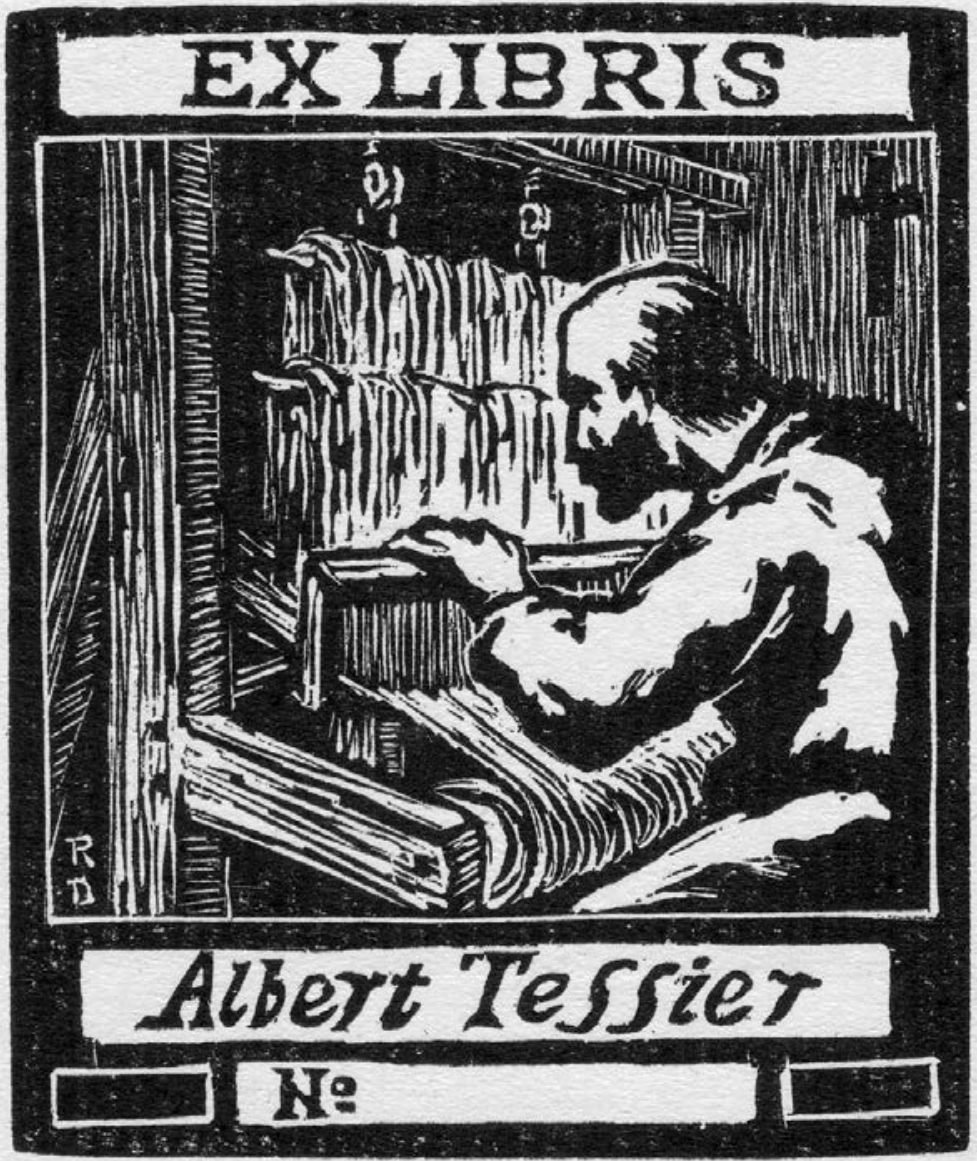

Figure 3. Rodolphe Duguay, Ex Libris Albert Tessier, gravure sur bois, 8,5 x 7,1 cm, vers 1935, ASTR, FAT, FN-0014-P3-38b. 
Le réseau français d'Albert Tessier compte ainsi plusieurs écrivains situant leur œuvre dans une région spécifique : Henri Pourrat (18871959) en Auvergne, Maurice Genevoix (1890-1980) en Sologne, François Porché (1877-1944) en Charente, Marie Le Franc (18791964) dans le Morbihan, en Bretagne, Georges Cerbelaud Salagnac (1906-1999) en Bretagne également, et le géographe Raoul Blanchard (1877-1965) dans la région Rhône-Alpes ${ }^{26}$. Tous ces auteurs entretiennent une correspondance avec l'abbé Tessier au cours des années 1930 et 1940 et ils ont tous séjourné en Mauricie, à l'exception de Salagnac.

Tessier connaît de façon empirique les enjeux de la médiation culturelle pour avoir lui-même importé au Québec des idées françaises. Après sa période mauricienne, il participe, à partir du Québec, à la transmission en France de l'idée d'un Québec de haute moralité et de saine nature. En s'adressant à des intermédiaires français, il s'immisce dans le processus de transmission comme un filtre entre la société visitée et les passeurs français ${ }^{27}$. Il agit sur les passeurs, sachant que le message est mieux reçu lorsqu'il est véhiculé par des individus appartenant à la culture réceptrice ${ }^{28}$. Dans la préface de son Rapport sur le tourisme de 1939, Tessier nomme ces passeurs qu'il cible comme intermédiaires : des intellectuels des milieux de la culture et de l'enseignement, en majorité du domaine littéraire :

${ }^{26}$ Un article anonyme de la Revue des deux mondes du 15 janvier 1941 dit que FrancNohain (Maurice Étienne Legrand [1873-1934]) est passé par la Mauricie, mais les documents du Fonds Albert-Tessier (FAT) ne permettent pas de savoir quelle était sa relation avec Tessier : "Après François Porché et Franc-Nohain, Maurice Genevoix s'arrêtera aux Trois-Rivières " (Archives du Séminaire de Trois-Rivières (ASTR), FAT, 0014-Q1-28).

27 Michel Espagne qualifie de « filtre » des agents qui transmettent des connaissances sur une culture étrangère sans quitter leur territoire, comme les enseignants de langue (Michel Espagne, "Quelques aspects actuels de la recherche sur les transferts culturels ", dans Lucile Arnoux-Farnoux et Anne Rachel Hermetet (dir.), Questions de réception, Paris, Société française de littérature générale et comparée (SFLGC), 2009, coll. "Poétiques comparatistes », p. 170).

${ }^{28}$ Charles Fouquet, "Qu'est-ce qu’un intermédiaire culturel? ", dans Vovelle (dir.), Les intermédiaires culturels, p. 619. 
À part la masse des promeneurs ordinaires et des amateurs de pêche ou de chasse, il y a les écrivains, les professeurs d'universités, de collèges et d'écoles primaires, les artistes, les cinéastes, etc., qui forment une classe choisie et qui sont plus sensibles que le commun des mortels aux charmes d'une contrée et d'une civilisation marquées de signes particuliers. Attirer ces gens-là chez nous, c'est faire de la publicité à répétition ${ }^{29}$ !

Tessier convient ainsi de la "vocation des écrivains à être des passeurs $^{30} "$, rôle qui leur est aujourd'hui reconnu ${ }^{31}$.

Le propagandiste envoie un choix de journaux, d'ouvrages et de l'information diverse sur le Québec et son histoire à ses correspondants français. Ses archives, actuellement conservées dans le Fonds AlbertTessier aux Archives du Séminaire de Trois-Rivières, révèlent que tous reçoivent de sa part les envois les plus divers, parmi lesquels Patrie intime de Nérée Beauchemin en $1928^{32}$, un recueil d'un poète mauricien dont Tessier fait la réclame. Blanchard remercie Tessier pour « l'avalanche de photos et publications ${ }^{33}$ ». Le Franc le remercie pour une gravure de Rodolphe Duguay : «Le Portageux? Il est sur le mur de mon logis, à côté de la forêt d'hiver et des étoiles de Duguay ${ }^{34}$. "

${ }^{29}$ Albert Tessier, "Préface du rapport sur le tourisme ", Rapport sur le tourisme, $2^{\mathrm{e}}$ éd., Québec, Ministère des Affaires municipales, de l'Industrie et du Commerce de la province de Québec, 1939, p. 1.

30 Diana Cooper-Richet, "Introduction ", dans Diana Cooper-Richet, Jean-Yves Mollier et Ahmed Silem (dir.), Passeurs culturels dans le monde des médias et de l'édition en Europe (XIX et XX siècles), Villeurbanne, Presses de l'École nationale supérieure des sciences de l'information et des bibliothèques (ENSSIB), 2005, p. 13-17.

31 Voir Cooper-Richet, Mollier et Silem (dir.), Passeurs culturels dans le monde des médias et de l'édition en Europe (XIX et XX siècles); Luneau et al., (dir.), Passeurs d'histoire(s); Angers et Fabre, Échanges intellectuels entre la France et le Québec (1930-2000).

32 Nérée Beauchemin, Patrie intime : harmonies, Montréal, Librairie d'Action canadienne-française, 1928.

33 Lettre de Raoul Blanchard à Albert Tessier, $1^{\text {er }}$ octobre 1937, ASTR, FAT, 0014P1-30.

34 Lettre de Marie Le Franc à Albert Tessier, 19 septembre 1936. Elle mentionne aussi les gravures de Duguay dans des lettres datées du 3 janvier et du 18 mai 1936 ainsi que du 17 janvier 1938, ASTR, FAT, 0014-P2-35. 
Porché est ravi de recevoir " une collection entière de feuilles d'érable ${ }^{35}$ ". Salagnac reçoit, en août 1941, sept ouvrages qui passent par le ministère des Affaires étrangères ${ }^{36}$. Les passeurs français viennent aussi puiser sur place, en compagnie de Tessier, une vision du Québec qu'ils répandent en France.

Les envois de Tessier à ses correspondants français et la majorité des échanges qu'il engage avec eux convergent vers un même but : faire la propagande d'une certaine image du Québec en France. Les idées et les inspirations que les passeurs français glanent au Québec à travers le filtre mis en place par Tessier sont de deux ordres : certains cherchent des arguments pour soutenir la doctrine patriotique et catholique en France, d'autres entretiennent l'image d'un pays de nature que la civilisation n'aurait pas corrompu.

\section{Quête d'une moralité catholique}

L'un des sujets d'échange, presque exclusivement épistolaire, se situe autour de valeurs morales partagées par le Québec et la France catholique. Tessier soutient des idées déjà répandues en France en fournissant un matériau qui répond aux attentes de ses interlocuteurs et qui est adaptable à la société d'accueil, selon le concept de remploi idéologique $^{37}$. Il profite du courant pour la restauration catholique entretenu par des groupes inquiets des bouleversements sociaux provoqués par la Première Guerre. Certaines mesures politiques mises en place par la Troisième République sont aussi perçues par ces groupes comme destructrices de la religion, des cultures et des langues régionales, car elles semblent faire peser une menace sur les valeurs traditionnelles. Les doctrines conservatrices soutiennent « l'obligation de solidarité avec l'Église catholique garante de l'ordre

35 Lettre de François Porché à Albert Tessier, 22 novembre 1925, ASTR, FAT, 0014-P2-101.

${ }^{36}$ Lettre de Georges Cerbelaud Salagnac à Albert Tessier, 12 août 1941, ASTR, FAT, 0014-P1-57.

37 Jean-Pierre Poitou, «Une histoire à étages? Sur la notion de remploi idéologique », dans Vovelle (dir.), Les intermédiaires culturels, p. 644. 
social et moral ${ }^{38}$ ", créant une situation propice à la réception, dans ces milieux, de l'image d'un Québec moral et religieux devant servir de modèle.

L’engagement de Tessier, qui se dit ouvert à la modernité, dans cette voie ultra-conservatrice semble moins paradoxal si nous tenons compte de ses motivations personnelles. Il semble, en effet, exploiter le besoin exprimé par la France catholique pour poursuivre le même objectif de renforcement de l'identité canadienne-française qui motivait déjà son action de médiateur culturel dans la première phase de sa carrière. Les échanges entre Georges Cerbelaud Salagnac et Tessier sont un exemple de la façon dont Tessier tire parti de ses relations françaises.

Cerbelaud Salagnac est l'un de ceux qui travaillent à la sauvegarde des valeurs traditionnelles et catholiques françaises. Sa fonction officielle de propagandiste au sein du gouvernement de Vichy en fait un passeur particulièrement bien placé :

J'appartiens maintenant au Secrétariat Général de l'Information, qui dépend directement de la Vice-Présidence du Conseil, et je suis détaché auprès des Chantiers de la Jeunesse du Languedoc pour la Propagande nationale, en vue de notre rénovation nationale et humaine ${ }^{39}$.

Voici les titres envoyés par Tessier pour servir l'œuvre de Salagnac :

J'ai reçu [...] hier : Mondes chimériques, de François Hertel; Mlle Sérénité de Moïsette Olier; Comme nous sommes heureux, de Jeanne l'Archevêque-Duguay [sic]; Courriers des villages, de Clément Marchand; Dimo de Sarah Larkin; Dans le bois, de Sylvain, et Trois-Rivières de vous-mêmes [sic], et je vous en remercie de tout cœur. Je vais lire cela et en ferai ici le meilleur usage. [...] Dans mes causeries, dans mes conférences, je donne constamment aux Jeunes de France l'exemple de l'Acadie et du Canada ${ }^{40}$.

${ }^{38}$ Géraldi Leroy, Les écrivains et l'histoire 1919-1956, Paris, Éditions Nathan, 1998, coll. « 128 », p. 21.

39 Salagnac à Tessier, 12 août 1941, ASTR, FAT, 0014-P1-57.

${ }^{40}$ Ibid. 
Michel Espagne considère que " les livres [...] sont l'un des vecteurs essentiels d'exportation ou d'importation d'éléments culturels d'un contexte dans un autre ${ }^{41} »$. Tessier transmet ainsi à ses intermédiaires français une image qu'il présente comme celle du Québec - qu'en France on nomme simplement "Canada " - en parlant presque essentiellement de la Mauricie, ne manquant jamais une occasion de favoriser son petit pays. Les titres envoyés indiquent qu'il privilégie les éditeurs trifluviens et les carrières mauriciennes, y compris la sienne $e^{42}$.

Salagnac, qui signe aussi « Hibou-Blanc chez les Scouts, et Frère Marc, au Tiers-Ordre de Saint Dominique ${ }^{43}$ ", écrit à Tessier que la France catholique a besoin d'un lien avec le Québec :

Plus que jamais, le Canada nous est cher et nous voudrions tant que la France réelle, enfin débarrassée de la fausse France légale des dernières années, soit dorénavant bien comprise de vous, Canadiens, dont l'exemple à travers les siècles nous est tant précieux. Car toutes ces vertus traditionnellement françaises que les Juifs et les Francs-Maçons, les communistes et les matérialistes ont voulu nous extirper, vous, vous les avez gardées pures et c'est à vous, en définitive, que nous devons les redemander!... Travail, Famille, Patrie, le tout couronné par Dieu, c'est le Canada qui nous en montre, à nous pauvres blessés encore affaiblis par le sang perdu, l'image fidèle et sans tache ${ }^{44}$.

${ }^{41}$ Espagne, "Quelques aspects actuels de la recherche sur les transferts culturels ", p. 168.

42 François Hertel, Mondes chimériques, Montréal, Valiquette, 1940; Moïsette Olier, Mademoiselle Sérénité, Trois-Rivières, Le Nouvelliste, c. 1936; Jeanne L'Archevêque-Duguay, Comme nous sommes heureux, Trois-Rivières, Bien public, 1940 ; Clément Marchand, Courriers des villages, Trois-Rivières, Bien public, 1940; Sarah Larkin, Dimo et autres histoires de bêtes, Trois-Rivières, Bien public, 1940 ; Sylvain [Dr Auguste Panneton], Dans le bois, Trois-Rivières, Éditions trifluviennes, 1940; Albert Tessier, Trois-Rivières : quatre siècles d'histoire, TroisRivières, Le Nouvelliste, 1935.

${ }^{43}$ Lettre de Georges Cerbelaud Salagnac à Albert Tessier, 6 janvier 1936, ASTR, FAT, 0014-P1-57.

44 Salagnac à Tessier, 12 août 1941, ASTR, FAT, 0014-P1-57. Lorsque Salagnac parle de " la fausse France légale ", il fait allusion à la Troisième République, à laquelle l'occupation allemande a mis fin. 
Cette idée d'un Québec de haute moralité exemplaire pour la France n'est pas répandue uniquement par Tessier ni propre à la période d'Occupation. Elle remonte au XIX ${ }^{e}$ siècle, à Rameau de Saint-Père ${ }^{45}$, et est bien vivante dans l'entre-deux-guerres. Georges Vattier fait valoir, dans son Essai sur la mentalité canadienne-française de 1928, que grâce à leur clergé, les Canadiens d'ascendance française «sont aujourd'hui un des peuples les plus religieux et les plus moraux de l'univers [...]. C'est donc à l'Église canadienne, écrit-il, que notre race et notre langue doivent incontestablement d'avoir survécu en Amérique $[\ldots]^{46} \%$. Un critique de l'époque commente l'essai de Vattier en ces termes :

Puis on se laisse aller au plaisir, mêlé d'envie, de comparer l'état religieux de la province de Québec à celui de la France et l'on rêve que des maux dont souffre notre pays lui auraient été épargnés s'il était demeuré fidèle aux croyances et aux traditions demeurées si vivantes sur les rives du Saint-Laurent ${ }^{47}$.

Une large part de l'intérêt de la France catholique à maintenir un lien avec le Québec réside dans cet objectif de revalorisation de la foi et des vertus traditionnelles en France. Les passeurs en contact avec Tessier recueillent du matériel dont ils se serviront pour donner le Québec en exemple afin de valoriser une identité française fondée

45 Voir Pierre Trépanier, "Rameau de Saint-Père, la France et la vie intellectuelle en Amérique française ", dans Yvan Lamonde et Didier Poton (dir.), La Capricieuse (1855): poupe et proue : les relations France-Québec (1760-1914), Québec, Les Presses de l'Université Laval, 2006, coll. "Cultures québécoises ", p. 285-305.

46 Georges Vattier, Essai sur la mentalité canadienne-française : contribution à l'étude de la psychologie des peuples, préface de l'Honorable M. Raoul Dandurand, Ministre d'État canadien, Paris, Librairie ancienne Honoré Champion, 1928, cité dans Henri Bourde de La Rogerie, "Georges Vattier : Essai sur la mentalité canadiennefrançaise et Esquisse historique de la colonisation de la province de Québec (16081925)", Revue d'histoire de l'Église de France, vol. 15, n 69 (1929), p. 505. Consulté dans Persée : portail de revues en sciences humaines et sociales, [http://www.persee.fr/ web/revues/home/prescript/article/rhef_0300-9505_1929_num_15_69_2523_ t1_0504_0000_1] (5 février 2012).

47 Bourde de La Rogerie, "Georges Vattier », p. 504. 
sur la foi et les valeurs morales ancestrales. Bernard Lamizet explique comment les passeurs agissent sur l'identité :

En rendant intelligible la culture qu'ils transmettent [ici la culture canadienne-française], les passeurs de culture nous font mesurer sa singularité et sa différence par rapport à la nôtre [la culture française]. Il y a, en ce sens, dans le rôle des passeurs culturels, quelque chose de la construction d'une identité qu'ils transmettent ${ }^{48}$.

En présentant le Québec comme le descendant désormais appelé à soutenir l'aïeule, Tessier sert la France, mais il sert surtout la cause identitaire qu'il défend. Il amène en effet la France à confirmer et même à consolider l'identité québécoise traditionnelle non seulement en France, mais aussi au Québec où ce discours français valorisant l'identité traditionnelle sera entendu.

Selon une idée répandue dans les milieux français qui s'intéressent à l'Amérique à l'époque, les qualités de simplicité, d'authenticité, de franchise et de piété se seraient conservées au Québec grâce à la foi, mais aussi grâce à l'influence bénéfique de la nature encore sauvage du pays. Tessier profite de cette conception française du Québec pour mettre en valeur les grands espaces de lacs et de forêts de la Mauricie.

\section{Visiteurs en quête de la nature québécoise}

L'abbé Tessier entretient des liens plus étroits avec des intellectuels catholiques de gauche. Il adapte son discours à leurs attentes lorsqu'ils voyagent au Québec sous sa gouverne. Il exploite l'attrait qu'exerce sur les Français la nature québécoise; il en fait un objet privilégié de ses rapprochements avec eux. Ses visiteurs témoignent d'un vif intérêt pour la forêt et ceux qui l'habitent : bûcherons, défricheurs, trappeurs et guides. Tessier organise pour ses visiteurs des expéditions dans les campagnes ou les forêts de la Haute-

48 Bernard Lamizet, "Chapitre 9: Le miroir culturel : les "passeurs" ", dans CooperRichet, Mollier et Silem (dir.), Passeurs culturels dans le monde des médias et de l'édition en Europe (XIX'e et XXe siècles), p. 169. 
Mauricie. Le géographe Raoul Blanchard confirme l'importance des activités d'hôte de Tessier :

[C'] est à lui que s'adressent les Français en quête de la NouvelleFrance et qui arrivent un peu désorientés aux rives du Saint-Laurent; et il les accueille, les conseille, les promène, les renseigne. J'ai été un de ces chançards qu'Albert Tessier a pris sous sa protection et en leur nom à tous je lui tire mon chapeau en disant : $\operatorname{merci}^{49}$ !

Dans ses relations avec les passeurs français, Tessier est avantagé par sa connaissance de la France régionale. Sa position antérieure de médiateur culturel entre le régionalisme provençal et le Québec lui permet, comme l'explique Laurier Turgeon à propos des théories sur le métissage et l'hybridation, « de bénéficier d'une double vision des choses, d'investir deux lieux en même temps et de devenir un intermédiaire incontournable ${ }^{50} »$.

Les excursions que Tessier organise pour ses visiteurs servent de matériau de base à des publications scientifiques ou littéraires diffusées en France. Elles servent aussi de monnaie d'échange à Tessier qui demande à ses invités des conférences ou des écrits qui soutiennent son action régionaliste et identitaire, tout en participant au maintien des idéaux français en Amérique. Tessier possède un talent particulier pour rallier les gens utiles à la cause qu'il défend. Dans l'avant-propos de La Mauricie, publié en 1950, Blanchard note, en parlant de Tessier :

Tous ceux qui le connaissent ne s'étonneront pas que je sois tombé sous le charme de cet incomparable animateur. J'ai eu à m'en repentir le jour où il s'est mis en tête de me faire écrire sur la région du Saint-Maurice. [...] Il faudrait une volonté de fer pour résister à l'abbé Albert Tessier; ce n'est pas mon cas. J'ai cédé; avec lui, j’ai visité de nouveau la vallée jusqu’à Windigo ${ }^{51}$.

49 Raoul Blanchard, "Mon ami Monseigneur Albert Tessier ", Ecclesia Canada, janvier 1961, ASTR, FAT, 0014-Q1-4.

50 Laurier Turgeon (dir.), Regards croisés sur le métissage, Québec, Centre interuniversitaire d'études sur les lettres, les arts et les traditions (CELAT) et Les Presses de l'Université Laval, 2002, coll. «Intercultures », p. 5.

51 Raoul Blanchard, "Avant-Propos ", La Mauricie, Trois-Rivières, Éditions du Bien public, 1950, p. 7. Tessier demande à Blanchard cet ouvrage sur la Mauricie lors d'une visite de la région avant la Deuxième Guerre mondiale. Blanchard annonce 
Tessier exploite au maximum le potentiel de ses visiteurs et amis sans ménager par ailleurs ses efforts pour les aider. Par exemple, en plus d'accompagner Blanchard dans son voyage, il lui procure de la documentation $^{52}$. Un exemplaire de l'ouvrage Le Centre du Canada français de 1947 conservé aux Archives du Séminaire de Trois-Rivières est dédicacé en ces termes : «À l'ami Albert Tessier. Sa victime, Raoul Blanchard $^{53}$. » (voir la figure 4). Une victime consentante et même complice, semble-t-il, puisqu'après leur séjour en Abitibi, il signe une lettre en utilisant la drôle de formule : «Tibissime, Raoul le Mauricien ${ }^{54}$ ».

Le professeur apporte au Québec des bases scientifiques au développement de la géographie et rapporte en France un portrait de la nature québécoise et de ses habitants, ses ouvrages comportant des études sur l'agriculture, les mours, l'histoire, l'économie, l'industrie, etc. Un regard sur les lieux et les dates de ses publications entre 1930 et 1950 indique que Blanchard publiait les deux tiers de ses ouvrages sur le Québec en France ${ }^{55}$.

La nature sauvage inspire également des romans parmi lesquels La randonnée passionnée de Marie Le Franc, publié à Paris en $1936^{56}$, dont le point de départ est une excursion en forêt à l'été de 1935, avec l'abbé Tessier, le guide Doré Gariépy et le botaniste montréalais Georges Préfontaine. Tessier lit le roman dédicacé par l'auteure en y

sa visite pour le 14 ou le 15 septembre 1937, et Tessier lui demande un texte le $1^{\text {er }}$ octobre (ASTR, FAT, 0014-P1-30; Albert Tessier, "Une amitié partagée " [hommage à Raoul Blanchard], tapuscrit, 24 novembre 1965, ASTR, FAT, 0014P1-30). Tessier réitère sa demande en 1948 lors d'un séjour en Abitibi (Lettres de Raoul Blanchard, 19 janvier et 21 avril 1948, ASTR, FAT, 0014-P1-30). Le voyage aura lieu et le géographe écrit à Tessier le 20 janvier 1949 qu'il travaille en même temps sur l'Abitibi et sur la Mauricie. Le premier paraît en 1949 à Grenoble (s. n., Impr. Allier), le deuxième en 1950, à Trois-Rivières.

52 Blanchard, "Avant-propos », p. 7.

53 Raoul Blanchard, Le Centre du Canada français, "Province de Québec ", Montréal, Beauchemin, 1947, ASTR, FAT.

${ }^{54}$ Lettre de Raoul Blanchard à Albert Tessier, 8 juin 1950, ASTR, FAT, 0014-P1-30.

55 Nous avons relevé neuf publications en France (cinq à Grenoble, quatre à Paris), six au Québec (cinq à Montréal et une à Trois-Rivières) et une dans les deux pays (Paris et Montréal).

56 Marie Le Franc, La randonnée passionnée, Paris, Ferenczi, 1936. 


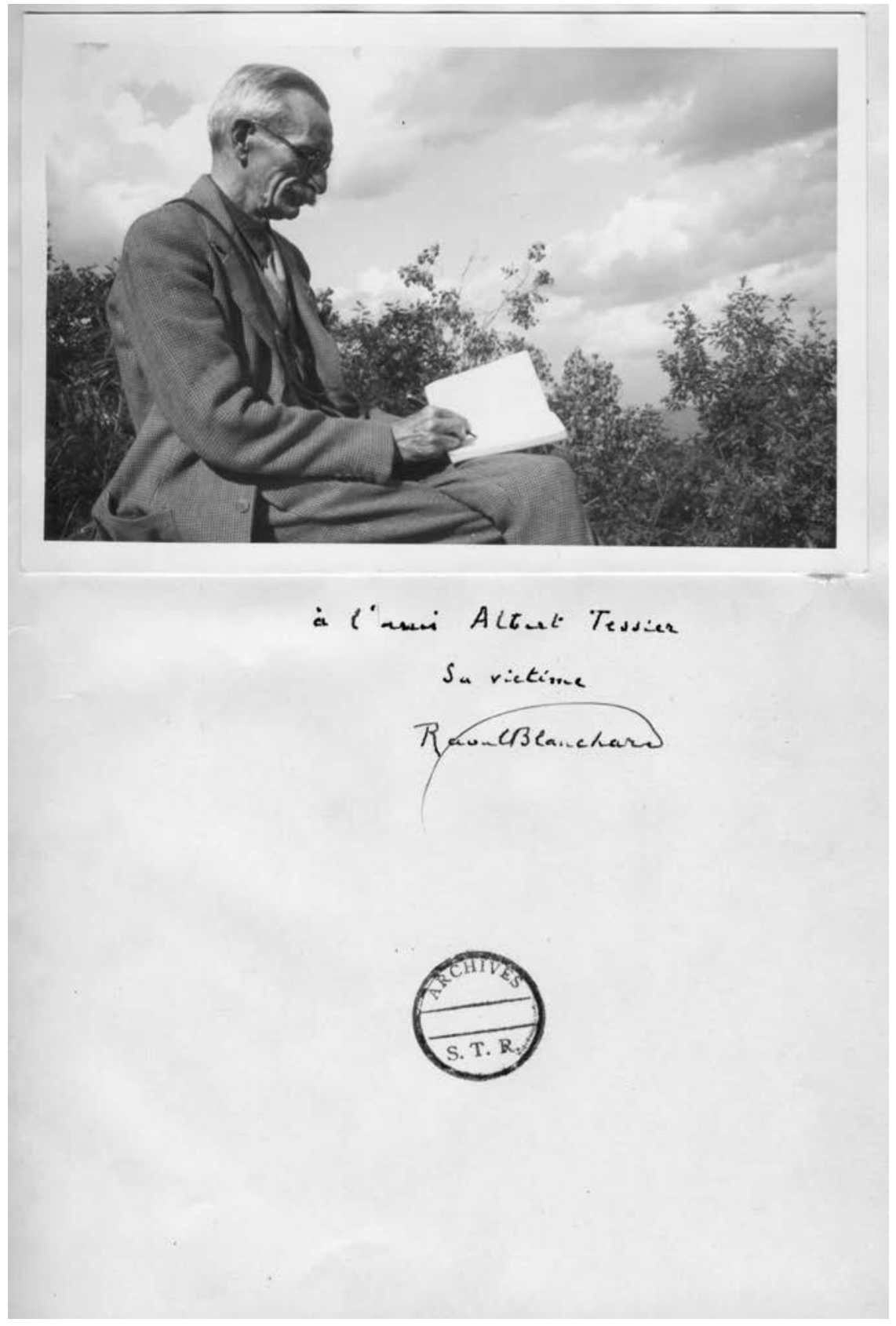

Figure 4. Raoul Blanchard, "À l'ami Albert Tessier. Sa victime, Raoul Blanchard ", page de garde avec dédicace de l'auteur et photographie collée par Albert Tessier, dans Raoul Blanchard, Le Centre du Canada français : "Province de Québec ", Montréal, Beauchemin, 1947, ASTR, FAT, Bibliothèque, rayon 56. 
collant seize photographies prises au cours de l'excursion ${ }^{57}$ (voir la figure 5). Il souligne et annote le texte comme le ferait un correcteur, marquant son acquiescement d'un «Bien » ou d'un "Superbe », et exprimant sa désapprobation par des points d'interrogation ou d'exclamation qui font à l'occasion office de jugements de valeur ${ }^{58}$. Une lettre de Marie Le Franc à Albert Tessier datée du 22 novembre 1935 laisse croire que Tessier aurait fait auparavant des suggestions à l'auteure, qui seraient cependant arrivées trop tard pour être intégrées à la publication ${ }^{59}$.

Tessier tient dans le roman le rôle de "l'abbé Beaudoin " (voir la figure 6). "On l'appelait parmi l'élite "le Mistral du SaintMaurice" 60 ", écrit l'auteure, qui transpose sur son personnage la mission que s'est donnée Tessier de travailler au "réveil de la race ${ }^{61}$ " en présentant des films sur le pays, la nature et les « habitants ». Le personnage de Grey Heron endosse la même mission : "Je rêvais d'être une espèce de missionnaire parmi ceux que je considère comme de ma race [...]. Je voulais les relever, les sauver. [...] [J']essayais de réveiller en eux l'énergie et la fierté des ancêtres ${ }^{62}$. " Marie Le Franc ramène ainsi en France des propos typiques du discours que Tessier avait emprunté à Frédéric Mistral. Elle joue de surcroît son rôle de médiatrice en faisant la réclame de la littérature québécoise en France. Par exemple, elle met en scène, dans La rivière Solitaire, le personnage d'Anne qui lit un roman d'Edmond Grignon ${ }^{63}$.

57 Exemplaire annoté et illustré par Albert Tessier (ASTR, FAT, 0014-P2-35).

58 Nous pouvons, par exemple, sentir qu'il désapprouve la façon dont Philippe Jarl, un personnage de La randonnée passionnée, conduit sa vie familiale.

59 Lettre de Marie Le Franc à Albert Tessier, 22 novembre 1935, ASTR, FAT, 0014-P2-35.

${ }^{60}$ Le Franc, La randonnée passionnée, p. 171.

61 Ibid., p. 170.

${ }^{62}$ Marie Le Franc, La randonnée passionnée, Montréal, Fides, 1961, p. 80-81.

${ }_{63}$ Marie Le Franc, La rivière Solitaire, Paris, Ferenczi, 1934, p. 179. Lauteure ne donne pas la référence exacte. Dans le roman, Anne lit «En attendant les ours », du «Dr H. Grignon ». Il s'agit, en fait, d'Edmond Grignon [Vieux Doc], En guettant les ours : mémoires joyeux d'un médecin des Laurentides, Montréal, Beauchemin, 1930, et Montréal, Édouard Garand, 1930. 


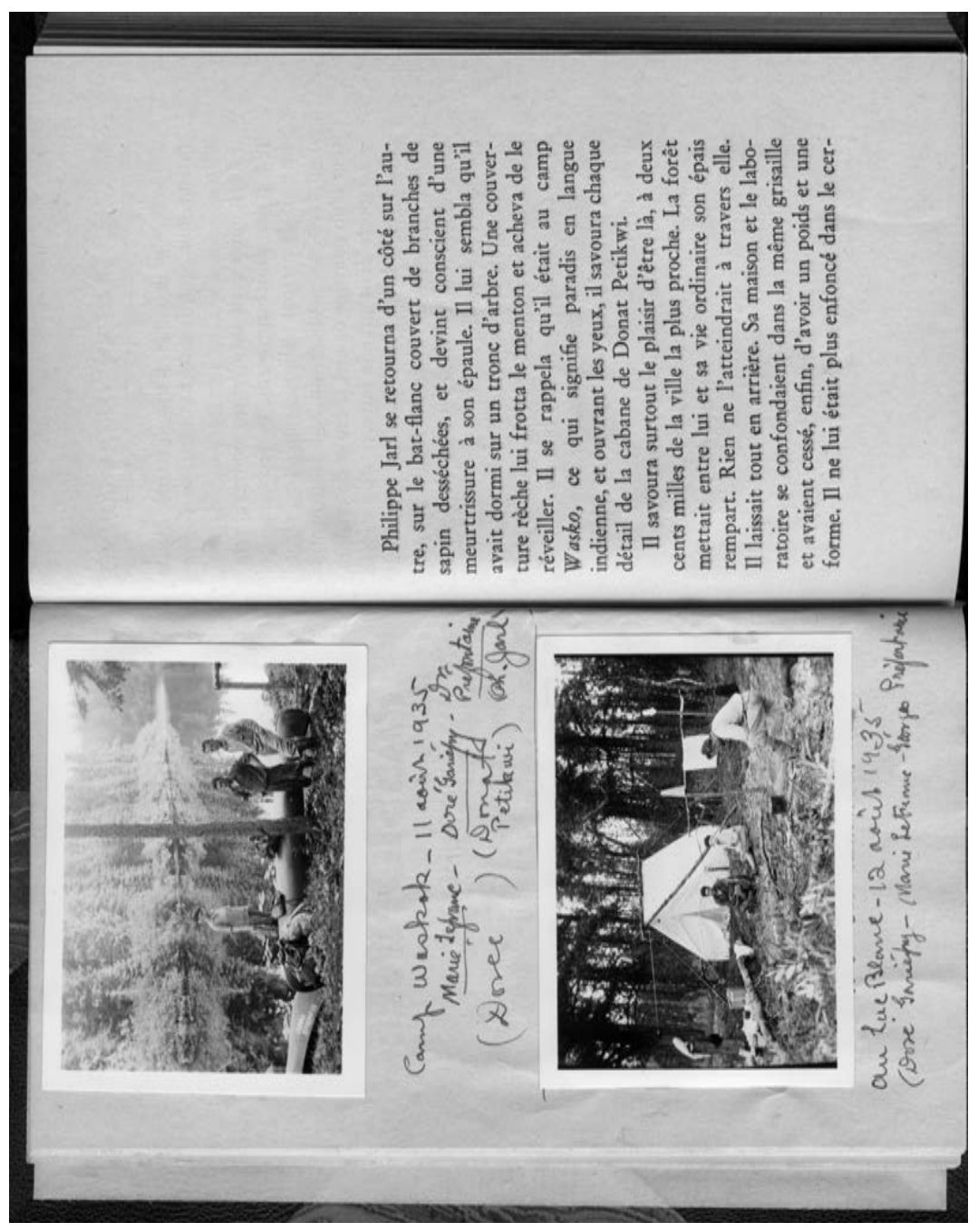

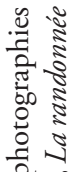

iे

结

$\approx$

롱

$\sim \sum^{2}$

ㄱ

บ

สิ

๑

ช

$\exists \stackrel{1}{\pi}$

ष

¿

沓

in

2 踏

寻艺

옹

二

जै

퐁

*

ํㅡㄹ

ชี

$\approx .1$

.

经

氙

过

เ $\frac{\pi}{2}$

$\because$

玨 


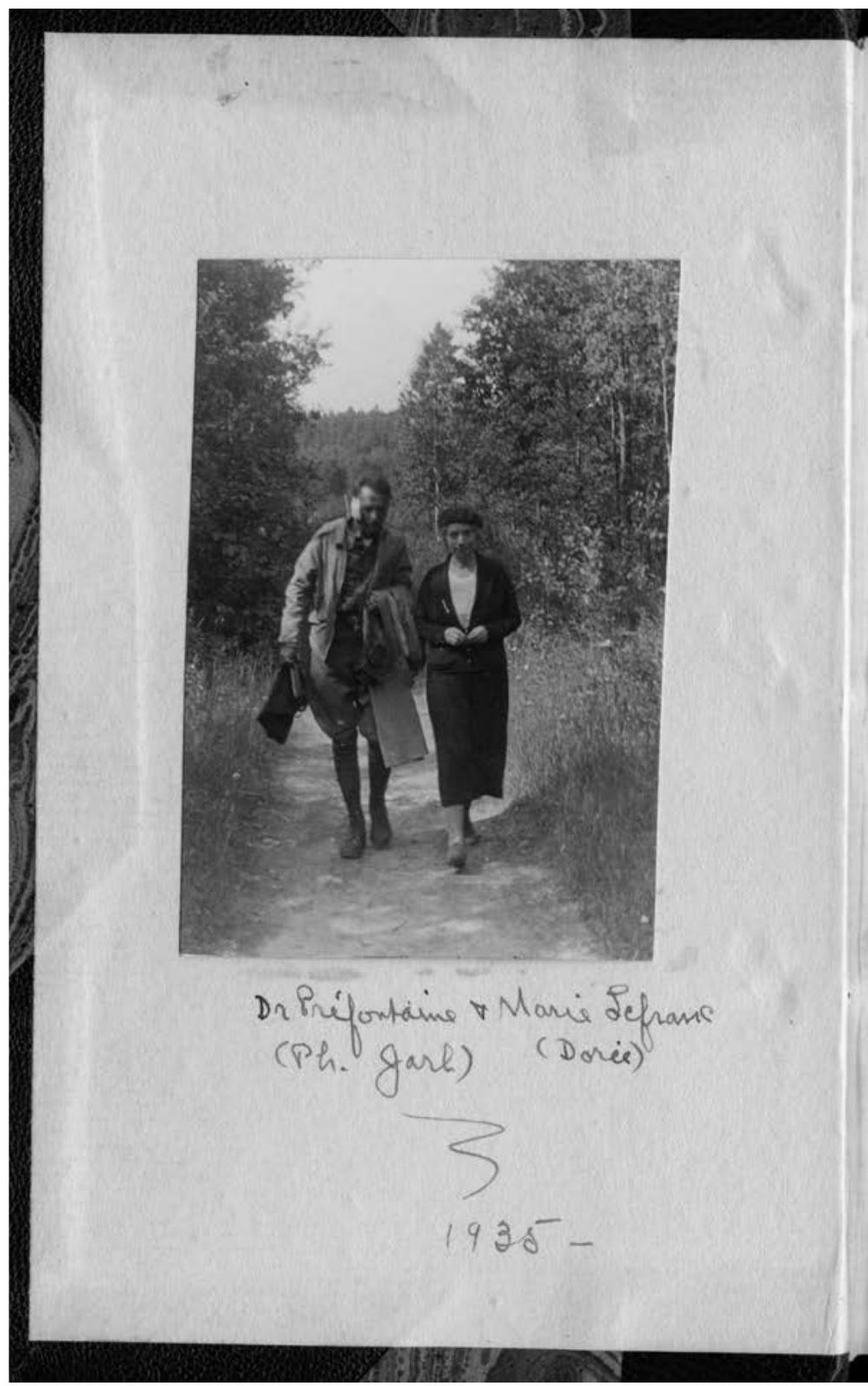

Figure 6. Albert Tessier, «Dr Préfontaine \& Marie Lefranc $[$ sic $]$ » et annotations " Abbé Beaudoin = Abbé Albert Tessier, (p. 167- 180 etc...) », photographie collée sur la page 
lehrs vesois.th

Liminaine

Srois- Pivieres

Oh. . .ort = Nor Prifontaine

Ubbere Prandoin = A bhe acher

(h.167-180 ete.-) Tesous

Doré - Marie Le Franc

Récir d.un voyase dans le dowh St-Maurie.

$0014-P 2-35$

intérieure de la couverture et annotations inscrites sur la page de garde de Marie Le Franc, La randonnée passionnée, Paris, Ferenczi, 1936, ASTR, FAT, FN-0014-P2-35. 
des, et au-dessus le visage étoilé du ciel. La neige collée aux troncs par petites plaques qui de loin faisaient l'effet de lumineuses petites fenêtres. La grande paix de tout cela, la fraternité parfaite, l'entente massive! Il viendrait souvent en souvenir frotter son front à ces étoiles.

Donat lui glissa quelque chose dans la main.

- Vous allez emporter ça avec vous.

C'était le précieux gobelet en bois d'érable qu'il portait à sa ceinture.

Quand ils arrivèrent, les autres les attendaient devant le bungalow. Une buée bleue montait de la terre, enveloppant les îlots de jeunes buissons. La nuit était d'une émouvante douceur. Donat hissa les bagages sur ses épaules et prit les devants. Sa puissante silhouette se détacha sur le ciel d'un bleu intense. Elle dominait la cuve déboisée à la lisière de laquelle il marchait comme au bord d'un lac d'un azur irréel, qui eût perdu sa menace et son venin. Pour la première fois, la forêt reculait, se laissait vaincre par ce « portageux 》 solitaire qui cheminait sous les étoiles. Le fardeau de ses épaules augmentait sa puissance. Jarl l'appela en son cœur le porteur de peine. Cela durerait ainsi jusqu'à la fin des temps, mais celui-ci re-

Figure 7. Albert Tessier, annotations « Bois gravé de Duguay : le Portageux ", dans Marie Le Franc, La randonnée passionnée, Paris, Ferenczi, 1936, p. 216, ASTR, FAT, FN-0014-P2-35. 
L'art plastique québécois participe aussi à l'œuvre de Marie Le Franc qui écrit à Tessier, en parlant de la gravure de Rodolphe Duguay qu'il lui a donnée : "Ce Portageux m’a forcée à ajouter une note à mon livre ${ }^{64}$ ", note que Tessier identifie dans la marge (voir les figures 7 et 8$)$ :

Donat hissa les bagages sur ses épaules et prit les devants. Sa puissante silhouette se détacha sur le ciel d'un bleu intense. Elle dominait la cuve déboisée à la lisière de laquelle il marchait comme au bord d'un lac d'un azur irréel, qui eût perdu sa menace et son venin. Pour la première fois, la forêt reculait, se laissait vaincre par ce " portageux » solitaire qui cheminait sous les étoiles ${ }^{65}$.

Roger Vercel, de l'Académie de Bretagne, écrit : «L'œuvre de Marie Le Franc est ainsi un système d'échanges entre les deux mondes. La voyageuse revient de Montréal et de la forêt canadienne où, comme une abeille, elle s'est chargée activement de butin ${ }^{66}$. " Elle puise au Québec, à travers le filtre des parcours suggérés par Tessier, la matière d'ouvrages qu'elle diffuse en France. En effet, avant 1950, on compte une vingtaine de ses publications en France pour quatre au Québec.

Les descriptions de Marie Le Franc s'articulent autour d'une opposition entre la décadence de la civilisation et la noblesse de la vie près de la nature. Une thèse largement répandue en France veut que la vie urbaine, en ne respectant pas les cycles de la nature, provoque le déclin de la vitalité de la population et la décadence du pays ${ }^{67}$. L'auteure dit de Hélier, dans Hélier fils des bois, publié en 1930 et 1935 aussi à Paris : «Il raisonnait avec un instinct de primitif ${ }^{68}$. » Le

${ }^{64}$ Lettre de Marie Le Franc à Albert Tessier, 19 septembre 1936, ASTR, FAT, 0014-P2-35.

${ }_{65}$ Marie Le Franc, La randonnée passionnée, Paris, Ferenczi, 1936, p. 216.

66 [Anonyme], "Un roman mauricien de Marie Le Franc : analysé par l'écrivain Roger Vercel » [extrait " d'un numéro déjà ancien des "Nouvelles littéraires" »], Le Bien public, 21 novembre 1946, p. 1, Bibliothèque et Archives nationales du Québec, [En ligne], [http://collections.banq.qc.ca/ark:/52327/1936323\#] (5 février 2012).

67 Leroy, Les écrivains et l'histoire 1919-1956, p. 26.

68 Marie Le Franc, Hélier fils des bois, Paris, Éditions Rieder, 1930, p. 15; Paris, Ferenczi, 1935. 
Franc acquiesce à l'idée des vertus qui s'épanouissent au contact de la nature québécoise en posant, à la fin du roman, la différence entre l'héroïne française et le guide québécois : "Elle apportait avec elle un limon d'inquiétudes, le pus de civilisations malades, l'odeur de peuples mêlés sur la même litière ${ }^{69}$. " Quant à Hélier, " [il] était une réalisation fantastique de la forêt, un héros de légende nordique $[\ldots]^{70} »$. Les activités sportives pratiquées dans la nature québécoise prennent, aux yeux de l'auteure, un caractère plus sain qu'en France : "Ce sont les gens d'Europe qui se jettent dans le plaisir avec une sombre et maladroite avidité. Ici, il était d'abord un jeu, auquel on se livrait en riant, avec une maîtrise complète de soi. [...] Il ne menaçait pas l'équilibre ${ }^{71}$. " Marie Le Franc participe ainsi à la diffusion d'une image d'un Québec jeune et sain dont le caractère hautement moral n'est pas dû, cette fois, à la religion et aux qualités françaises ancestrales, mais plutôt à l'influence de la nature. Les personnages des bois qu'elle présente en France sont tous admirables à différents titres : ils ont pris au contact de la nature un caractère débrouillard, serein, authentique et simple.

Maurice Genevoix, écrivain régional républicain, publie aussi un roman inspiré d'une excursion en forêt en compagnie de l'abbé Tessier en 1939. Laframboise et Bellehumeur ${ }^{72}$ (voir la figure 9) est publié à Montréal et à Paris en 1941. Il publie par ailleurs le récit de ce voyage, dont une partie est consacrée à l'excursion mauricienne, à Paris en 1945 sous le titre Canada ${ }^{73}$. L'auteur demeure, dans cet ouvrage, très près de l'expérience vécue en Mauricie. Il y relate, par exemple, l'escalade d'une échelle de garde-feu dont témoigne une photographie de Tessier $^{74}$ (voir la figure 10). Ce dernier lit toujours

\footnotetext{
69 Marie Le Franc, Hélier fils des bois, Paris, Éditions Rieder, 1930, p. 275.

70 Ibid., p. 276-277.

${ }^{71}$ Ibid., p. 40.

${ }_{72}$ Maurice Genevoix, Laframboise et Bellehumeur, Paris, Éditions de l'Arbre, 1941.

73 Maurice Genevoix, Canada, Paris, Flammarion, 1945.

${ }^{74}$ Le Fonds Albert-Tessier contient de nombreuses photographies de Genevoix prises par Tessier (ASTR, FAT, 0014-Q3-173 et 0014-Q1-28).
} 

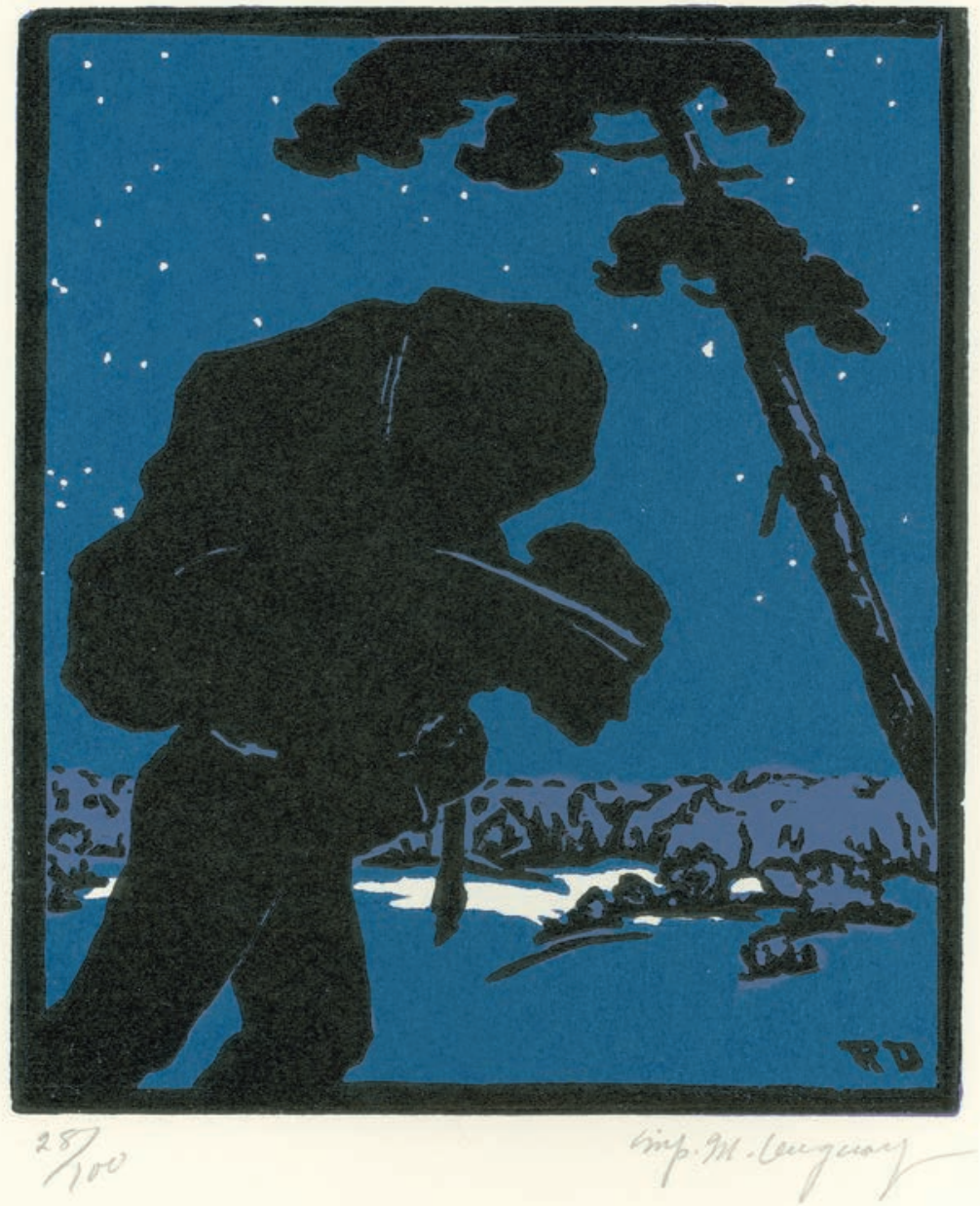

Figure 8. Rodolphe Duguay, Le Portageux, gravure sur bois (en bleu et noir), 11,5 x 9,9 cm, 1936, Québec, Bibliothèque de l'Université Laval, dans Jean-René Ostiguy, Rodolphe Duguay : vingt gravures de Rodolphe Duguay, portefeuille, Québec, Garneau, 1974, $14^{\mathrm{e}}$ feuillet. 
attentivement les livres de ses intermédiaires français, y note les passages qui l'intéressent, et dans le cas de Genevoix, les circonstances de sa rencontre avec l'auteur ${ }^{75}$ (voir la figure 11).

Lorsque l'abbé Tessier amène ses visiteurs français chez l'« habitant ", il joue un double jeu : il se fait médiateur culturel pour les Canadiens français et agent propagandiste auprès des Français. Il joue, d'une part, son rôle coutumier de médiateur culturel du régionalisme mistralien au Québec en présentant ses films sur la fierté nationale et le petit pays au public campagnard; il se fait, d'autre part, agent propagandiste auprès des passeurs français conviés à assister à sa mise en scène qui est, en somme, une représentation de l'identité canadienne-française telle qu'il la conçoit.

Ce moment du processus de transmission se révèle complexe si on y ajoute en plus la "double médiation, entre présentation et représentation ${ }^{76}$ ", que Lamizet explique en ces termes : " La présentation désigne la dialectique entre le singulier et le collectif, tandis que la représentation désigne l'autre dialectique, entre le réel et le symbolique ${ }^{77}$. " Tessier établit donc une double médiation pour son public canadien-français, en même temps qu'il transmet le spectacle et sa signification au passeur français qu'est Genevoix. À son tour, celui-ci se chargera, plus tard, de présenter et de représenter la culture canadienne-française, saisie à travers le filtre de Tessier, auprès des Français dans ses propres publications.

Genevoix témoigne, dans Canada, des circonstances de l'échange entre lui et la culture canadienne-française à travers le filtre mis en place par Tessier. Il raconte une tournée de conférences dans de petits villages, hors du circuit intellectuel habituel : «L'après-midi, l'abbé passait ses films. Le soir venu, je parlais ${ }^{78}$. "Tessier ne laisse pas ses visiteurs français entièrement libres, il les dirige vers ce qu'il considère

75 Canada, publié en 1945, est remis à Tessier en 1959 et annoté en décembre 1966.

76 Lamizet, "Chapitre 9 : Le miroir culturel : les "passeurs" ", p. 166.

77 Ibid., p. 164. Les italiques sont de Lamizet.

${ }^{78}$ Genevoix, Canada, p. 88. 


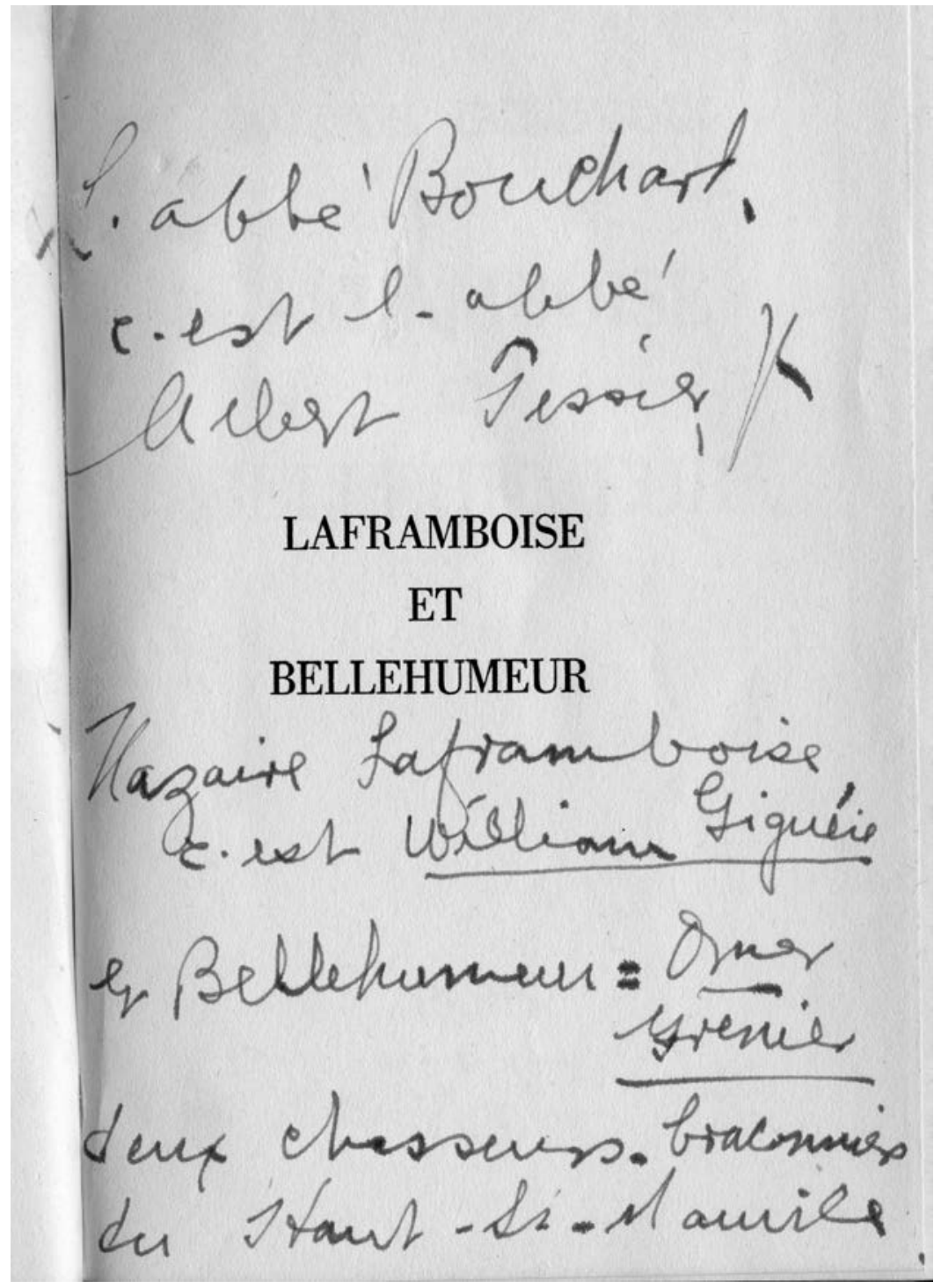

Figure 9. Albert Tessier, «L'abbé Bouchard, c'est l'abbé Albert Tessier, ptre », annotations avec identification des personnages, dans Maurice Genevoix, Laframboise et Bellehumeur, Paris et Montréal, Éditions de l'Arbre, 1941, page titre, ASTR, FAT, Bibliothèque, rayon 160 . 

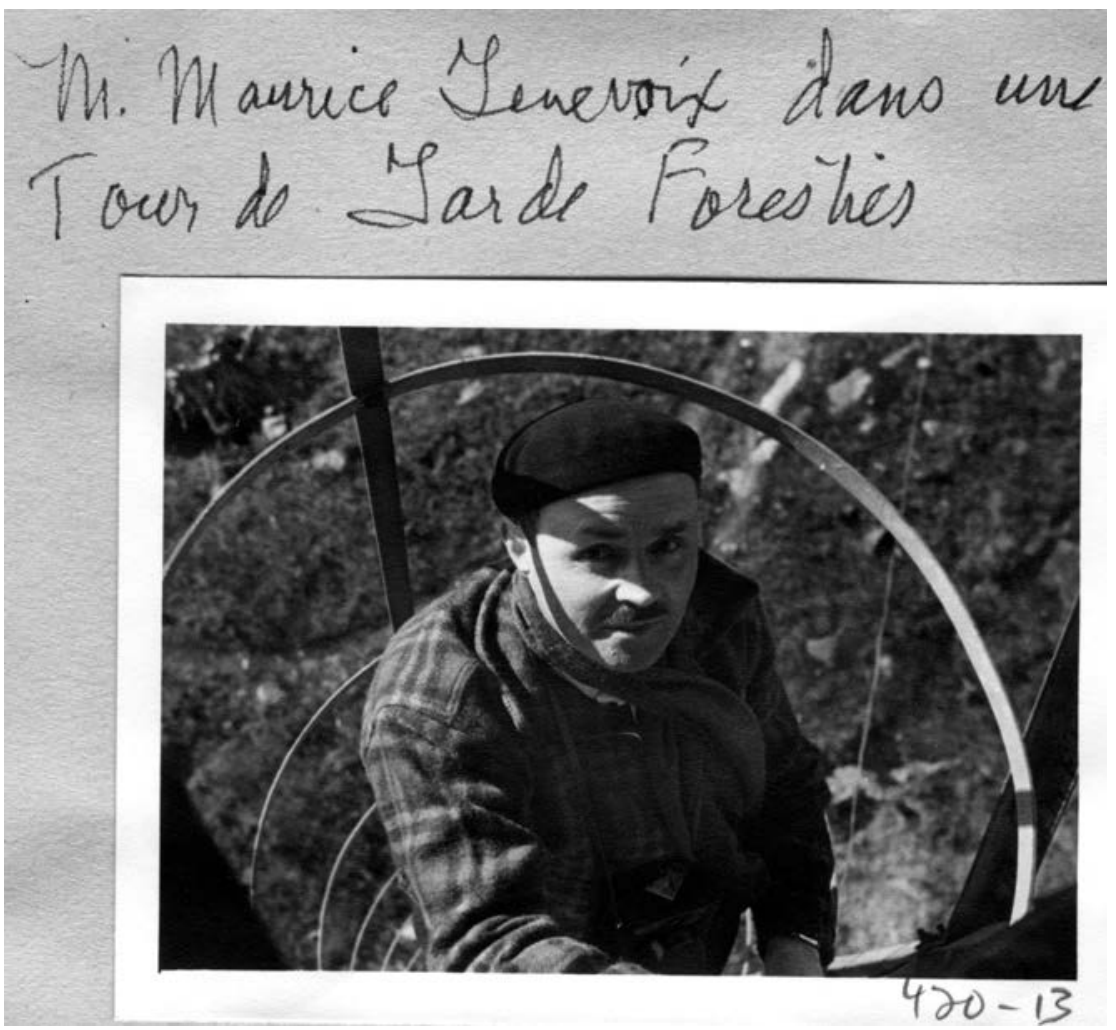

Figure 10. Albert Tessier, "M. Maurice Genevoix dans une tour de Garde Forestier », photographie, 1939, ASTR, FAT, FN-0014-Q3-173, image 420-13.

utile de leur montrer. À la question d'un interlocuteur anonyme : "Quelles raisons expliquent le choix de la Mauricie par Maurice Genevoix? », Tessier répond :

Monsieur Genevoix ne l'a pas choisie : j'ai choisi! Le séjour en Mauricie a duré une dizaine de jours. Durant cette période, monsieur Genevoix a vécu la vraie vie des bois et il s'est mêlé à la population pittoresque de nos forêts. [...] [Il] fut très marqué par la forêt mauricienne ${ }^{79}$.

Tessier ajoute que Genevoix " ne s'extériorisait pas beaucoup ", qu'il " enregistrait les moindres détails avec une fidélité exceptionnelle ${ }^{80}$ ", ce

\footnotetext{
79 Albert Tessier, " Maurice Genevoix raconté par Monseigneur Albert Tessier », tapuscrit non daté, ASTR, FAT, 0014-Q1-28.

${ }^{80}$ Ibid.
} 
Page 81:acommence e reicis de no he toun de Suebee.

En 1939, Mannice fencooi, un denil de sa 1 refermme. ful emverge an anada faur se mefoser. dem Bunchios me le Confia el, duranl phed d. un mois, fe le fromenari a travero la Provine et daus lesclubs de - Jear créte en Mauricie arbentenes pid dex 1966 -

Figure 11. Albert Tessier, «En 1939, Maurice Genevoix, en deuil de sa $1^{\text {ère }}$ femme, [...] déc. 1966 ", annotations de passages et circonstances de la rencontre de Maurice Genevoix, dans Maurice Genevoix, Canada, Paris, Flammarion, 1945, page de garde, ASTR, FAT, Bibliothèque, rayon 160. 
qui en fait à ses yeux un excellent intermédiaire. Cela n'empêche pas, toutefois, un glissement de sens du message dû à l'interprétation du passeur. Lamizet explique en effet que « la présentation de l'œuvre [ici, le film de Tessier] articule sa signification plastique et culturelle à ce qu'elle peut susciter chez chacun de ses visiteurs dans son inconscient, dans son expérience propre, dans la singularité de son expérience et de sa subjectivitée ${ }^{81}$ ». C'est ainsi que Genevoix reçoit l'expérience canadienne. Les réactions de la foule, lors d'une séance de projection dans la cour de la maison du père de l'abbé Tessier, le touchent particulièrement, ce qui lui fait écrire :

Plus que jamais, je songe à mon pays, mon pays absent et coupable. La conviction s'impose à moi que s'il existe, dans toute l'étendue de cet immense continent, un recours, un antidote contre les aveuglants dangers d'un américanisme qui se grise de ses excès mêmes, ils sont là, chez ce peuple canadien français [sic], français toujours... ${ }^{82}$.

L'auteur est ému par l'attachement des " habitants " à leurs valeurs et à leur culture, il admire la sagesse et la retenue de la culture populaire du Québec, qualités qu'il interprète comme un héritage français. Genevoix diffuse ainsi l'idée d'un Québec porteur de valeurs françaises. Au-delà de ce message voulu et approuvé par Tessier, une représentation française de la réalité canadienne s'immisce nécessairement dans les romans de Genevoix.

En plus de la part d'interprétation que recèle le discours des médiateurs, ces derniers sont tenus de l'adapter aux intérêts et aux besoins de ceux à qui il est destiné ${ }^{83}$. Le roman Éva Charlebois, publié à Paris et à Montréal en $1944^{84}$, se déroule en Amérique, mais relève cependant d'un déterminisme régionaliste de conception française.

${ }^{81}$ Lamizet, "Chapitre 9 : Le miroir culturel : les "passeurs" ", p. 165-166.

${ }^{82}$ Genevoix, Canada, p. 123-124. Les propos de Genevoix témoignent d'une inquiétude face aux développements de la modernité aux États-Unis, qu'il juge excessifs, et d'une certaine crainte du pouvoir grandissant de ce pays à la fin de la guerre.

${ }^{83}$ François Laplantine et Alexis Nouss, Le métissage : un exposé pour comprendre; un essai pour réfléchir, Paris, Flammarion, 1997, coll. "Dominos », p. 40.

${ }^{84}$ Maurice Genevoix, Éva Charlebois, Paris, Flammarion; Montréal, Valiquette, 1944. 
Née à Saint-Urbain dans la région de Charlevoix, Éva ne peut vivre loin du Québec malgré toute sa bonne volonté; elle ne s'adapte ni aux paysages des Rocheuses qui lui font peur, ni aux sonorités de la langue anglaise. Sa souffrance fait songer à celle qu'évoque Maurice Barrès, républicain vivant à Paris, incapable de se défaire de l'influence de sa Lorraine natale ${ }^{85}$. Ainsi, comme la terre d'origine détermine l'individu, selon une pensée communément répandue en France, Charlevoix détermine Éva Charlebois.

Pour des écrivains comme Le Franc face à la nature sauvage du Québec ou Genevoix face à la société rurale canadienne-française, il s'agit, comme l'explique Laurier Turgeon, "de la reconnaissance d'une particularité ethnique qui tend à accentuer leur différence et à renforcer les hiérarchies sociales en place ${ }^{86}$ ". Le Québec apparaît ainsi en France comme le pays primitif où sont conservées les valeurs françaises ancestrales.

\section{Le Québec, société-mémoire de la France}

Albert Tessier doit nécessairement tenir compte de ce que désirent ses contacts en se basant sur ce qu'il connaît des intérêts français largement diffusés au Québec. Il ne propose pas de son propre chef l'image d'un pays de haute moralité et de nature sauvage. Il répond, au contraire, à des demandes françaises et renvoie une image attendue qui correspond aux besoins de la société d'accueil.

Toucher terre d'Henri Pourrat n'est qu'un exemple parmi d'autres témoignant des appels lancés par la France traditionaliste à la culture canadienne-française " semblable à soi ». L'auteur y écrit :

Le Canada, grâce à ses littérateurs, devient pour les songes une province, semblable à soi [...]. Et elle a des couleurs faites pour plaire : à la fois jeunes, exotiques, d'un monde neuf, et puis anciennes, plus qu'en France; d'un vieux monde paysan ici trop souvent bousculé par le siècle ${ }^{87}$.

85 Barrès définit la Lorraine en ces termes : "pays de ma nécessité, pays qui m’est imposé " (Chiron, Barrès et la terre, p. 27).

86 Turgeon (dir.), Regards croisés sur le métissage, p. 9.

87 Henri Pourrat, "Vieux plant ", Toucher terre, Paris, Éditions Sang de la terre, 1986 [1946 / 1936], p. 77. 
Pourrat, gagné à l'idéologie du retour à la terre qui le rapproche de la conception du régionalisme que Tessier puise chez Mistral, conçoit un Québec ayant le potentiel d'une terre vierge et la sagesse d'un ancien mode de vie. Cet héritage français survivant au Québec apparaît propre à rétablir en France des valeurs que certains considèrent perdues. Pourrat résume la situation dans une métaphore :

C'est ainsi que là où la vieille vigne a disparu, remplacée par des variétés modernes, pour retrouver l'ancien plant aux fortes vertus, on va chercher dans les lieux écartés, dans les rapaillages. Et il se peut qu'on y trouve des pousses vigoureuses, là où les gens ont eu assez d'amour pour les respecter. Les frères canadiens peuvent beaucoup pour nous, $s^{\prime}$ ils le veulent ${ }^{88}$.

Tessier participe donc, avec beaucoup d'autres intellectuels de son époque, à la création d'une perception du Québec comme "sociétémémoire " de la France, c'est-à-dire, selon la définition de Pierre Nora, une société " à fort capital mémoriel et à faible capital historique $^{89}$ " sur laquelle on compte pour conserver les valeurs et les traditions culturelles d'un groupe. La culture canadienne-française sauvegarderait la mémoire de l'ancienne France en l'intégrant dans ses gestes, sa langue et ses habitudes. Dans cette perspective, le Québec devient un relais, pour utiliser un terme employé par Michel Espagne $^{90}$, entre la France contemporaine et l'ancienne France. Il est, en quelque sorte, une transcription de la France d'origine que des médiateurs français retransmettent à la France contemporaine. Cela s'avère aussi bien dans le cas des conservateurs nostalgiques d'une époque plus croyante que dans celui des modernes nostalgiques d'une nature primitive perdue.

88 Ibid., p. 81.

89 Pierre Nora, "Entre mémoire et histoire : la problématique des lieux ", dans Pierre Nora (dir.), Les lieux de mémoire, t. 1 : La république, Paris, Gallimard, 1984 , p. XVIII, XXV.

90 Espagne, "Quelques aspects actuels de la recherche sur les transferts culturels ", p. 177. L'auteur fait référence au concept de relais en décrivant le cas d'ouvrages traduits à partir d'une traduction. 
En tant qu'agent de transmission, Tessier se soucie moins de l'orientation politique de ses intermédiaires français que de la diffusion de l'identité et de la représentation canadienne-française en France. Son action est d'abord régionaliste, catholique et identitaire, et c'est en respectant ces valeurs qu'il cherche à donner une vision positive du Québec dans tous les milieux catholiques français auxquels il peut avoir accès. Tessier ne transmet pas d'idées nouvelles à la France, il ne fait que répondre à la demande : dans certains cas, celle d'un modèle de société catholique; dans d'autres, celle d'une société simple vivant en communion avec la nature.

La transmission de cette image du Québec en France n'est pas un transfert culturel à proprement parler puisqu'il n'est aucunement question d'implanter des idées nouvelles ou des éléments étrangers à la culture d'accueil. Nous pourrions, par contre, parler d'un retour du transfert culturel d'origine, surtout en ce qui concerne la propagande régionaliste d'Albert Tessier. Il s'agit en fait, pour plusieurs des passeurs français en relation avec ce dernier, de se réapproprier des valeurs perçues comme perdues en France. En ce sens, l'échange culturel passe de la France au Québec, qui se fait relais pour lui retourner certaines de ses valeurs traditionnelles. Tessier s'interpose alors comme un filtre entre le Québec et les passeurs Georges Cerbelaud Salagnac, Raoul Blanchard, Maurice Genevoix et Marie Le Franc pour présenter le Québec comme une "société-mémoire " de la France. Ce faisant, il poursuit toujours son objectif premier de renforcement de l'identité rurale et catholique du Canada français. Il espère, en effet, que l'image du Québec transmise par les passeurs influence le discours français, qui renverra à la société québécoise une image d'elle-même revalorisée.

Tessier tire habilement parti de ses contacts français, mais il ne ménage pas sa peine, par ailleurs, pour diffuser la pensée française en Amérique. Henri Pourrat reconnaît l'investissement de l'abbé Tessier dans l'effort de restauration de la France rurale catholique. Ayant reçu ses albums, il lui écrit le 18 septembre 1949 : 
Mon compliment le meilleur à l'auteur, et tous mes vœux pour sa grande ouvre. Je me dis que c'est une grande ouvre aujourd'hui de travailler pour la paysannerie française et l'idée chrétienne. Surtout à l'heure où s'affrontent formidablement les U.S.A. et l'U.R.S.S. Ni le dollar ni la faucille et marteau ne sauveront les hommes, ni leur apporteront la lumière et la paix. Il n'y a qu'une civilisation celle du Christ, notre Seigneur $[\ldots]^{91}$.

Les échanges entretenus par Tessier entre la France et le Québec sont récompensés par la France : il obtient en 1959 le Grand Prix de la langue française de l'Académie française et la médaille de la Ville de Paris pour sa contribution au progrès de la vie française au Canada ${ }^{92}$.

Après la guerre, Tessier perd peu à peu le contact avec les passeurs les plus à droite, dont l'influence s'amenuise en France. Les dernières lettres de Pourrat datent de 1953, celles de Salagnac, de 1944³. Il entretient ses liens avec Genevoix et Blanchard, des intellectuels politiquement plus neutres qui ne sont pas compromis par la collaboration, jusqu'au milieu des années $1960^{94}$. Leurs rapports prennent cependant une tournure plus personnelle. Il perd le contact avec Marie Le Franc en 1946, sans doute faute de véritables points communs avec la romancière ${ }^{95}$. La fonction de "visiteur en chef des écoles ménagères » à partir de 1947 amène Tessier à s'intéresser, dans les années 1950 et 1960, à l'éducation des jeunes filles et au rôle de la femme dans la famille. Son réseau se déplace à cette époque vers les sciences sociales.

${ }^{91}$ Lettre d'Henri Pourrat à Albert Tessier, 18 septembre 1949, ASTR, FAT, 0014P2-103.

92 Panneton et Magnan, "Prélats de la Maison du Pape : Tessier (Monseigneur Albert) ", p. 30.

93 Les périodes de contact sont établies à partir des dates extrêmes de la correspondance conservée aux Archives du Séminaire de Trois-Rivières : avec Pourrat, 1928 à 1953; avec Porché, 1923 à 1937; avec Salagnac, 1935 à 1944 (Martine Maher-Bussières et Christian Lalancette, Répertoire du Fonds Albert-Tessier FN0014, Trois-Rivières, Archives du Séminaire de Trois-Rivières, 2006).

${ }_{94}$ Tessier est en contact avec Genevoix de 1939 à 1966 et avec Blanchard, de 1933 à 1965.

${ }^{95}$ La correspondance avec Marie Le Franc va de 1935 à 1946. 
Le travail mériterait d'être poursuivi du côté de la France pour obtenir une synthèse de la réception et des résultats de la transmission de l'image du Québec comme pays de nature et de haute moralité. Déterminer plus précisément les réseaux dans lesquels Tessier est intégré et tenir compte du contexte français, particulièrement en ce qui concerne la position politique ou religieuse des passeurs et des médiateurs au cours des années 1930 et 1940, donnerait une meilleure idée de l'impact de la participation de Tessier à la transmission de cette image du Québec vers la France.

Cette exploration du point de vue d'un agent de transmission travaillant par l'intermédiaire de passeurs confirme l'intérêt de saisir le transfert culturel comme un processus dont les divers moments révèlent des influences importantes ou de nouveaux rôles. Des chercheurs intéressés aux transferts culturels proposent des notions qui peuvent s'appliquer de façon nouvelle. Ainsi en est-il de la notion de filtre de Michel Espagne, qui peut s'étendre à l'agent transmetteur de sa propre culture, ou de celle de relais, également d'Espagne, qui peut s'appliquer à une communauté culturelle. 